\title{
Epidemiology of human African trypanosomiasis
}

This article was published in the following Dove Press journal:

Clinical Epidemiology

6 August 2014

Number of times this article has been viewed

\section{Jose R Franco' \\ Pere P Simarro' \\ Abdoulaye Diarra ${ }^{2}$ \\ Jean G Jannin'}

'World Health Organization, Control of Neglected Tropical Diseases, Innovative and Intensified Disease Management, Geneva, Switzerland; ${ }^{2}$ World Health Organization, Inter Country Support Team for Central Africa, Regional Office for Africa, Libreville, Gabon
Correspondence: Jose Ramon Franco World Health Organization, Control of Neglected Tropical Diseases, Innovative and Intensified Disease Management, 20 Av Appia, I21 I Geneva, Switzerland Tel $+4 \mid 227913313$

Fax +4I 227914777

Email francoj@who.int
Abstract: Human African trypanosomiasis (HAT), or sleeping sickness, is caused by Trypanosoma brucei gambiense, which is a chronic form of the disease present in western and central Africa, and by Trypanosoma brucei rhodesiense, which is an acute disease located in eastern and southern Africa. The rhodesiense form is a zoonosis, with the occasional infection of humans, but in the gambiense form, the human being is regarded as the main reservoir that plays a key role in the transmission cycle of the disease. The gambiense form currently assumes that $98 \%$ of the cases are declared; the Democratic Republic of the Congo is the most affected country, with more than $75 \%$ of the gambiense cases declared. The epidemiology of the disease is mediated by the interaction of the parasite (trypanosome) with the vectors (tsetse flies), as well as with the human and animal hosts within a particular environment. Related to these interactions, the disease is confined in spatially limited areas called "foci", which are located in Sub-Saharan Africa, mainly in remote rural areas. The risk of contracting HAT is, therefore, determined by the possibility of contact of a human being with an infected tsetse fly. Epidemics of HAT were described at the beginning of the 20th century; intensive activities have been set up to confront the disease, and it was under control in the 1960 s, with fewer than 5,000 cases reported in the whole continent. The disease resurged at the end of the 1990s, but renewed efforts from endemic countries, cooperation agencies, and nongovernmental organizations led by the World Health Organization succeeded to raise awareness and resources, while reinforcing national programs, reversing the trend of the cases reported, and bringing the disease under control again. In this context, sustainable elimination of the gambiense HAT, defined as the interruption of the transmission of the disease, was considered as a feasible target for 2030. Since rhodesiense HAT is a zoonosis, where the animal reservoir plays a key role, the interruption of the disease's transmission is not deemed feasible.

Keywords: human African trypanosomiasis, HAT, sleeping sickness, Trypanosoma brucei gambiense, Trypanosoma brucei rhodesiense

\section{Introduction}

Human African trypanosomiasis (HAT), also known as sleeping sickness, is a vectorborne parasitic disease caused by an extracellular protozoa belonging to the genus, Trypanosoma, species, brucei. Two subspecies of Trypanosoma brucei are pathogenic for humans: T. $b$. gambiense and T. $b$. rhodesiense. These two parasites cause distinct pathologic entities, both of which are included under the general term HAT, but they have to be considered as two separate diseases, with different epidemiological and clinical patterns and different patient management. ${ }^{1}$

T. b. gambiense infection is found in western and central Africa, and it usually causes a chronic disease named gambiense HAT. ${ }^{2}$ It is an anthroponotic disease with 
a minor role for animal reservoirs. It is responsible for $98 \%$ of the cases of HAT reported in the last decade. ${ }^{1}$

T. b. rhodesiense is found in eastern and southern Africa. It is less adapted to human beings and it causes an acute and rapidly progressive disease, known as rhodesiense HAT. ${ }^{2}$ It is a zoonotic disease, affecting mainly animals (livestock and wildlife), with humans being only accidentally infected. Rhodesiense HAT has an epidemic potential in humans, as it has been responsible for large outbreaks in the past. ${ }^{3-5}$

The classical geographic separation of the two forms of the disease approximately coincides with the Rift Valley, with $T . b$. rhodesiense present at the east of the Rift Valley, while T. b. gambiense is found to the west of the Valley. Due to different factors, the gap between the two forms has been reducing in Northwest Uganda and on the border between the United Republic of Tanzania and the Democratic Republic of Congo, and in the future, an overlap of the two forms could occur. ${ }^{6}$

\section{General clinical aspects}

HAT clinically evolves in two stages. Initially, there is a first or early stage, where parasites dwell in the lymphatic system and bloodstream (hemo-lymphatic stage). ${ }^{1,2}$ After a variable period, which is much shorter in rhodesiense HAT than in gambiense HAT, a late or second stage starts when the trypanosomes cross the blood-brain barrier and invade the central nervous system (meningo-encephalitic stage), accompanied by progressive neurological damage. ${ }^{1,2}$ HAT is considered to be usually fatal if left untreated; ${ }^{7}$ patients progress gradually to a coma, severe organ failure, and eventually death.

The clinical presentation of HAT varies in the two forms of the disease. The signs and symptoms are generally the same for both forms, but they differ in terms of their frequency, severity, and kinetic appearance. Rhodesiense HAT is an acute disease that usually progresses to death within 6 months. ${ }^{8}$ Gambiense HAT has a more chronic progressive course with an average duration of almost 3 years. ${ }^{9}$

The clinical signs and symptoms are unspecific in both forms of the disease, and their appearance varies between individuals and foci. Intermittent fever, headache, pruritus and other dermatologic problems, lymphadenopathies, weakness, asthenia, anemia, cardiac disorders, endocrine disturbances, musculoskeletal pains, and hepatosplenomegaly are the main signs and symptoms of the first stage. ${ }^{1}$ Neuropsychiatric signs and symptoms, including sleep disturbances, are characteristic of second stage. ${ }^{1}$ However, most of the symptoms of both stages overlap, rendering the distinction between the stages, made based on clinical features, unclear. Misdiagnosis with other fever-causing diseases and neuropsychiatric problems is frequent. ${ }^{10,11}$

\section{Transmission cycle}

In both forms of HAT, infection occurrence depends on the interaction of three elements within a particular environment:

1. The mammalian reservoirs of parasites (human or animal) that can be also the host suffering from the disease, and which are influenced by their behavioral interactions with the environment;

2. Tsetse flies or Glossina as cyclical vectors for transmission that are fully dependent on environmental factors; and

3. The pathogenic parasite, the trypanosome.

Due to reasons that are not always well known, but that are related to the interactions between these three elements, the transmission of the disease is confined in areas with quite clear spatial limits, beyond which the disease does not occur. This limited space is called a "focus". ${ }^{12}$

\section{The parasite: Trypanosoma brucei}

HAT is caused by protozoans hemoflagellates of the genus Trypanosoma. There are many species of trypanosomes, ${ }^{1}$ but only two subspecies of the $T$. $b$. group are responsible for sleeping sickness: T. $b$. gambiense and T. b. rhodesiense. A third subspecies of the group, T. b. brucei is nonpathogenic for humans, but parasitizes domestic (Bovidae, Suidae, Canidae) and wild animals and it is widely used in experimental models of HAT. ${ }^{13}$ Trypanosomes are extracellular parasites and they can be clearly identified microscopically, but the two subspecies that are pathogenic for human beings are morphologically indistinguishable. ${ }^{1,12}$

Since differences between these subspecies cannot be observed by microscopy, other methods have been used; apart from the geographic differences, the specific molecular marker known as the serum resistance-associated (SRA) gene is currently being used to differentiate between the species, as it is always present in all T. b. rhodesiense isolates. ${ }^{14} T$. $b$. gambiense has been characterized by another specific molecular marker, the TgsGP gene, found in type $1 T$. b. gambiense. ${ }^{15}$ This form constitutes the classical form of gambiense HAT. A much more uncommon type $2 T$. b. gambiense found in western and central Africa does not contain the TgsGP gene ${ }^{16}$ and it produces a more acute form of gambiense HAT.

T. brucei group trypanosomes are transmitted by tsetse flies. They have a complex life cycle, ${ }^{17-23}$ with differentiated 
biological stages in both the insect vector and the mammalian host.

When entering in the Glossina, the parasites are ingested as bloodstream trypomastigote forms and they move to the midgut. Some species of tsetse are refractory to infection by specific species of trypanosome and even when they are susceptible, the population of parasites in the midgut can be reduced making unsustainable the infection at this point. ${ }^{21,23,24}$ However some of the trypomastigote forms in the insect's midgut may arrive to differentiate into procyclic forms, which replicate in situ and cross the peritrophic membrane to reach the proventriculus, where they becomes mesocyclic trypomastigotes and later epimastigote forms. ${ }^{17-19,22,23}$ Then, they migrate via the esophagus, proboscis, and hypopharynx to the salivary gland, where they are able to multiply and some of them can transform into infectious metacyclic forms. ${ }^{17-19,23}$ During this migration from the midgut to the salivary glands, the parasite population size experiences a pronounced reduction. ${ }^{21-23}$ The metacyclic form is the only stage that is infective to vertebrates, and it is characterized by the presence of the variant surface glycoprotein (VSG) coat that will protect the parasite in order to survive on the host. ${ }^{17-20}$ The whole cycle in the vector takes $18-35$ days, and once infected, a tsetse fly remains so for the rest of its lifespan. Nevertheless, in lab conditions it has been observed that the majority of ingested trypanosomes fail to develop, and only $2 \%-5 \%$ of the flies ingesting trypanosomes produce metacyclic forms. ${ }^{18}$

Metacyclic forms are injected subdermally in the mammalian host during a tsetse fly's blood meal. They proliferate at the site of inoculation and they transform in long slender forms, as they are carried by the draining lymph nodes to the bloodstream where they replicate. ${ }^{17,20}$ In the bloodstream, the parasite can be found in its proliferative, long, slender bloodstream trypomastigote form, which is adapted to maintain the parasite in mammalian blood, or as the nonproliferative, short, stumpy bloodstream trypomastigote form, which is adapted to differentiate into the replicative procyclic form in the tsetse fly, and thus to ensure transmission. ${ }^{17,20}$ There are also intermediate forms, which are transitional, as they are between the slender and stumpy forms. The bloodstream forms can enter into different body fluids, including lymph and cerebrospinal fluid, and they can also cross the placenta. ${ }^{1,2}$

Sexual reproduction is not obligatory in trypanosomes, but it can occur in salivary glands, ${ }^{25,26}$ yielding the possibility of genetic exchange and the rapid transmission of important characteristics, such as drug resistance and virulence. ${ }^{26}$
Genetic exchange is relatively frequent in $T . b$. rhodesiense, but it is more sporadic in $T . b$. gambiense. ${ }^{27}$

The amount of parasites in the bloodstream (parasitemia) is generally very low in $T$. b. gambiense infections, often remaining below 100 parasites per $\mathrm{mL}$ of blood, while in T. b. rhodesiense, infections typically present with higher parasitemia. ${ }^{28}$ Nevertheless, in both cases, parasitemia undergoes important fluctuations; low parasitemia levels can make it complicated to see parasites through microscopy.

The fluctuations of parasitemias are related to host immune responses and the antigenic variation presented by the parasites. ${ }^{29}$ The surface of bloodstream forms of trypanosomes is covered with a glycoprotein coat (VSG), which keeps antibodies and the complement system away from the parasite membrane. ${ }^{30-32}$ The host develops an effective antibody response, mainly through immunoglobulin $\mathrm{M}$ and immunoglobulin G, against this highly immunogenic VSG. Most antibodies of the host are able to disrupt the protective shield and kill the parasites, decreasing the number of parasites present. Nevertheless, the coat protein can turn over very rapidly, leading antibodies that are bound to the surface to be wiped out and permitting the parasites to escape the immune response at a given time. There are a large number of genes with the potential to encode the VSG, carrying the possibility of producing new variants almost ad infinitum. ${ }^{30-33}$ There is also an internal mechanism that regulates shifting to new variants: the parasites release a "stumpy induction factor", which triggers the production of nonreplicating stumpy forms, adapted to reestablish the life cycle when ingested by the tsetse fly. ${ }^{34}$

\section{The vector: Glossina spp.}

HAT is transmitted through the bite of an infected tsetse fly (genus Glossina). Thirty-one species and subspecies of tsetse flies have been described and classified in three groups or subgenera, ${ }^{35}$ which are generally related to different habitats:

- Subgenus Nemorhina, or the palpalis group, found in western and central Africa, live in vegetation close to a water source, such as forests, gallery forests, riverbanks and lakes, swamps and mangroves, coffee or cocoa plantations, and they can even adapt to environmental changes, surviving in the periurban areas of medium and large towns ${ }^{36}$ and areas of intensive agriculture. This subgenus includes the main vectors of sleeping sickness: G. palpalis palpalis and G. p. gambiensis for T. b. gambiense and G. fuscipes for both T. b. gambiense and T. b. rhodesiense. G. palpalis is distributed in the Atlantic coast from Senegal to Angola. G. fuscipes is present in central Africa from Cameroon and Congo to the Rift Valley. 
- Subgenus Glossina sensu stricto, or the morsitans group, occurs in woodland savannah, and is linked to the presence of wild fauna and cattle. G. morsitans, G. swynnertoni, and G. pallidipes, all of which are located mainly in East Africa, might be involved in the transmission of T. $b$. rhodesiense.

- Subgenus Austenina, or the fusca group, lives in primary forest belts (rainforest, savannah, or coastal forests). Increasing human activity in these forests tends to make this subgenus disappear. They have not been reported to be vectors of HAT.

Tsetse flies are restricted to sub-Saharan Africa, between the latitudes of $14^{\circ} \mathrm{N}$ and $29^{\circ} \mathrm{S}$, south of the Sahel desert, and north of the Namibian and Kalahari deserts. ${ }^{37}$ Some pockets of G. morsitans and G. fuscipes have been described in southwestern Saudi Arabia. ${ }^{38}$ All the species of tsetse flies are potentially cyclical vectors of trypanosomes, but in nature, the infection is carried almost exclusively by G. fuscipes, G. palpalis, and G. morsitans.

Tsetse flies need a particular temperature $\left(16^{\circ} \mathrm{C}-38^{\circ} \mathrm{C}\right)$ and humidity ( $50 \%-80 \%$ of relative humidity) to survive. Therefore, they are linked to the presence of water that increases the local humidity, allowing for the growth of vegetation that protects them from direct sunlight and wind, and attracts the animals to where tsetse feed. ${ }^{1}$

The transmission of HAT involves the obligatory biological development of trypanosomes in the fly, as previously described, and in only $2 \%-5 \%$ of cases will this development occur, with the presence of metacyclic forms in the salivary glands. Therefore, the mature infection rate among tsetse flies is quite low, with an average of less than $1 \%$ of tsetse flies infective for T. brucei spp. ${ }^{39}$ This makes the tsetse fly a relatively low competent vector for trypanosomiasis transmission. Nevertheless, even the low ingestion of parasites during the blood meal can result in infection in the fly, ${ }^{40}$ and a single infected tsetse bite is sufficient for transmitting the infection to another mammalian host. ${ }^{41}$ However, the probability of the transmission of HAT is related to the number of trypanosomes inoculated into the mammal. Therefore, the capacity of transmission of the disease by the tsetse fly is influenced by different factors, such as the density of tsetse populations, the tsetse fly's longevity, the vector's susceptibility to infection, the tsetse fly's infestation rates, the availability of other sources of a blood meal, and the factors that determine the frequency and intensity of the host-fly's contacts. ${ }^{24,28,35,42}$

The life cycle of Glossina is peculiar because of the absence of oviposition and the development of a single larva in the uterus of the female fly. Each female produces one single offspring at a time and the third instar larva developed within the uterus is larviposited as a mature larva into humid soil in a shady place. The larva moves actively, and then it quickly buries itself a few centimeters deep in clay or sandy soil to pupate. The pupa lives in the soil on the food reserves, and the adult insect emerges 20-80 days after larviposition, depending on temperature and humidity. ${ }^{1}$

The female is mated in the days following her emergence, and only one insemination is generally sufficient for her to remain fertile, but in some cases, young females accept several sexual unions. The female accumulates the spermatozoids in the spermathecae where they can survive for nearly 200 days. The female deposits a larva approximately every 10 days. ${ }^{1}$

The lifespan of the fly is highly variable depending on the season: longer in the rainy season (3-5 months) and shorter in the dry season (1-2 months), rarely exceeding 7 months. In general females live longer than males, being more numerous in natural populations. ${ }^{1}$

Both female and male flies are hematophagous and, thus, both are capable of transmitting infection. Newly emerged flies (teneral flies) need to immediately find a host on which to feed, and they are not very discriminatory about the host. The chance of becoming infected is highest in this first blood meal, ${ }^{43}$ but tsetse flies can be infected with trypanosomes at any point in their lives. Meals are taken about every $2-4$ days (up to 10 days when climatic conditions or the availability of hosts is adverse). ${ }^{1}$ Tsetse fly saliva is injected during the blood meal to avoid blood coagulation and to produce a vasodilation. If the saliva contains infective trypanosomes, they are transferred during the meal. If the host is infected by trypanosomes, these are ingested by the fly and it can develop an infection but as already indicated the majority of ingested trypanosomes fail to develop.

The feeding preferences of tsetse flies are not well known; odor stimuli produced by cutaneous secretions, feces, urine, and breath, as well as visual factors related to form, size, movements, contrast, and color are involved in the finding of a suitable host. ${ }^{44,45}$ These aspects have led to the development of different vector control tools. ${ }^{45-47}$ Suidae (pigs, warthogs, and bush pigs) are regarded as the first preference for G. morsitans and G. palpalis, and reptiles (monitor lizards, crocodiles, and snakes) are preferred by many species, but in general, tsetse flies are opportunistic and are able to adapt to host availability. ${ }^{1}$ Some wild animals (kob, zebra, wildebeest, oryx) are rarely ever bitten by tsetse flies, possibly because their colors are less attractive, or because their skin contains repellent substances ${ }^{48}$ Humans are occasionally bitten by the morsitans group, although the human odor acts as a repellent. ${ }^{49,50}$ 
G. fuscipes and G. palpalis seem to be attracted to human odor. ${ }^{51}$ The palpalis group is more opportunistic, and it feeds more indiscriminately on many species. ${ }^{52}$

The blood meal lasts between $20-30$ seconds. ${ }^{1}$ The tsetse flies can be killed by the defensive movements of the host. Thus, they prefer to bite animal hosts on the lower parts of the anterior legs or on the belly, where they are less likely to be killed. ${ }^{1}$ This behavior is the basis upon which to propose the restrictive application of insecticides to only those parts of cattle to decrease costs and increase effectiveness. ${ }^{53,54}$

The tsetse fly spends most of its time resting, with daily flying activity of 30-50 minutes in males and only a few minutes in females, mainly concentrated in the morning and at the end of the afternoon; the flies do not leave their resting places during the hottest parts of the day or during the rain, or in windy conditions. ${ }^{55}$ They fly at low levels $(\sim 0.5 \mathrm{~m})$ and at high speeds (up to $25 \mathrm{~km} /$ hour) in small successive displacements of a few seconds or minutes, usually covering short distances (200-300 m). However, they have a great capacity to disperse, and they can cover up to 20-30 km of distance in successive days. ${ }^{28}$ They can be passively transported by cattle herds or on vehicles, boats, or trains, with the risk of reinvading areas free of tsetse. ${ }^{1}$

Resting places include the underside of leaves, branches, the holes in tree trunks, roots, or other shady areas, but they also rest in sunny places in the early morning. ${ }^{1}$ During the dry season, the resting places are below $50 \mathrm{~cm}$ during the day, but at night or during the rainy season, they are at around $2.5 \mathrm{~m}$, sometimes reaching up to $10 \mathrm{~m}$. Knowledge about the resting places of tsetse flies determines the use of the selective application of insecticide ground spraying and sequential insecticide aerial treatments. ${ }^{1}$

Densities of tsetse populations are determined by climatic, environmental factors and host availability, but in general, the tsetse population growth tends to be low, as this is mainly related to their low reproductive rate. ${ }^{1}$ Since Glossina is practically the only vector responsible for transmitting the parasite from one mammalian host or reservoir to another, combining its control with the detection and treatment of cases of infection can contribute to the sustainability of HAT control.

\section{The reservoir and the host: the human being in the cycle of human African trypanosomiasis}

The role of animal reservoirs and human beings is very different in the two forms of HAT. Gambiense HAT is an anthroponotic disease with a minor role for animal reservoirs, while rhodesiense HAT is a zoonotic disease, affecting mainly animals (livestock and game); humans are only accidental hosts.

\section{Gambiense human African trypanosomiasis}

It is typically regarded that humans constitute the main epidemiological reservoir of T. b. gambiense. ${ }^{1,35}$ Despite the fact that the tsetse fly has a relatively low competence as vector for gambiense HAT, and the presence of parasitemias in human beings is usually low, the long duration of human infection with an extended paucisymptomatic period is considered sufficient to maintain a human-fly-human transmission cycle. ${ }^{56}$

Nevertheless, some data ${ }^{16,57,58}$ suggest the possible role played by asymptomatic human beings or animals as additional reservoirs. Asymptomatic individuals infected with trypanosomes who refused treatment and were followed-up for long periods (5-15 years) without showing any clinical manifestation of the disease have been described. ${ }^{59}$ These individuals can become aparasitemic by microscopy, while keeping a polymerase chain reaction intermittently positive and a trypanolysis test positive. ${ }^{60}$ They could be asymptomatic chronic carriers of the infection, and a source of vector infection that maintains the transmission of gambiense HAT in some cases. ${ }^{61}$ This could be similar to the phenomena of trypanotolerance, which is well described in animals. ${ }^{62,63}$

The other hypothesis relies on the possible role played by a variety of domestic and wild animals (mammals and reptilians) as reservoirs. T. b. gambiense has been described in domestic animals such as pigs, sheep, dogs, goats, and many different wild animals. ${ }^{64-74}$ The role played as reservoirs by these animal hosts is not clear; in some gambiense human foci, T. b. gambiense group 1 parasites are found in domestic livestock (mainly pigs), but in other foci where the same infection is present in humans, the parasites have not been found in domestic animals. ${ }^{74,75}$ On the other hand, in some foci, the infection rates and trypanosome genotypes circulating in pigs and humans are different, suggesting that the pig may not act as an animal reservoir for human infections in this focus. ${ }^{70}$ There are also some studies relating the prevalence of gambiense infection in domestic animals and that of gambiense HAT in humans, ${ }^{73}$ and which have not found the parasite in wild animals in sites where there are no human cases. ${ }^{72}$ Some studies show that experimental infections of animals with T. b. gambiense are limited in time, always lasting less than 1 year. ${ }^{76}$ Therefore, more data are needed to clarify the role played by the animal reservoir in maintaining gambiense transmission when the prevalence of human infection is low and elimination is envisaged. 
In addition, HAT control programs that target only the human reservoir through case detection and the subsequent treatment of cases without including vector control activities have been very successful, as the disease has reached very low prevalence rates after several rounds of active case finding ${ }^{77-79}$ and, in some cases, achieving even elimination. ${ }^{80}$ However, in other foci, despite active case detection that has been maintained over many years, ongoing transmission continues and the prevalence figures have remained the same. ${ }^{81,82}$ In these cases, the persistence of the transmission and maintenance of the prevalence rate may also be linked to incomplete attendance of population to screening activities and to the limited sensitivity of the diagnostic methods used..$^{79,83,84}$

\section{Rhodesiense human African trypanosomiasis}

The transmission cycle of $T$. $b$. rhodesiense mainly involves the transmission between nonhuman reservoirs through the tsetse fly, but occasionally humans can be included in the cycle, although their role as reservoirs is limited:

- Animal-tsetse fly-animal: this is the usual cycle.

- Animal-tsetse fly-human: this occasionally happens.

- Human-tsetse fly-human: this is very unlikely and probably only happens during epidemics.

The population of $T$. $b$. rhodesiense is, therefore, maintained in nonhuman reservoirs. In some cases, the animal just carries the parasite and survives for many years, but in other cases, the animal is affected by the disease. Carriage of T. b. rhodesiense has been confirmed in the following wild animals: ${ }^{1}$ bushbuck; duiker; giraffe; hartebeest; hyena; impala; lechwe; lion; oribi; reedbuck; warthog; waterbuck; and zebra, with bushbucks considered as the most frequently described reservoir. Domestic animals, such as bovine and porcine species, have also been identified as reservoirs. ${ }^{85-87}$ The existence of a reptilian host has been well described, but its contribution to the maintenance of trypanosomes is unlikely, as their body temperature varies considerably, making the survival of parasites improbable. ${ }^{88}$

Hence, two situations can be differentiated: there may be areas where the main reservoirs are wild animals; and there may be areas where domestic animals play this role. These two different situations are related to different risks of transmission, and these risks are crucial when considering control measures.

In the case of areas where wild animals can act as the main reservoir, different factors can facilitate the involvement of the human being in the transmission cycle of rhodesiense HAT. These factors are related to the increase of contact between human and wild animal reservoirs. Land-use pressures trigger the use of new areas for domestic animal grazing; thus, domestic animals invade areas that are occupied by wildlife, increasing the possibility of the transmission of rhodesiense HAT from wildlife to humans, either directly or passing the disease through livestock. Another example is the case described where tourists and rangers visit or work in protected areas. ${ }^{11,89}$ In some areas, wild animals formerly acted as the main reservoir for the parasite, but the habitats of these animals were colonized by human activities, and domestic animals substituted wildlife, subsequently becoming the main reservoirs. ${ }^{1}$

In the case where cattle serve as the main reservoir, the contact between humans and the reservoir is easier, and outbreaks of the disease in humans can easily occur. This contact can be even peridomestic. Cattle infection with T. b. rhodesiense has accounted for around $1 \%$ of livestock infections in areas where human cases are rarely reported, ${ }^{87}$ but this rate can reach $18 \%$ during human outbreaks. ${ }^{90}$

\section{Other atypical transmission routes}

The principal mode of transmission of HAT is vector-borne by tsetse fly. The tsetse fly is considered as a cyclical vector as the transmission requires a transformation process of the parasite in the fly. In the case of high parasitemias, the mechanical transmission of the infection by tsetse flies could be possible but very rare and it has already been described for $T . b$. rhodesiense. ${ }^{91}$

Other less frequent routes of transmission have been described:

- Vertical transmission of the infection is well known, and has been demonstrated in cases where individuals have been diagnosed with HAT in the days following birth, and in infected children born in nonendemic countries from infected mothers. ${ }^{59,92-94}$ Congenital transmission is assumed to be rare, but it occurs more often than currently thought, although it is frequently underdiagnosed because of the poor capacities of the health care facilities available in endemic areas, the unspecific clinical symptoms and signs of the disease, the lack of awareness among the staff members who attend to newborns, the important number of deliveries that occurs outside these health care facilities, and the high infant mortality rate in the endemic areas related to different causes. ${ }^{94}$

- Accidental mechanical transmission in laboratories has very rarely occurred. ${ }^{95}$

- The infection can be acquired through blood transfusion, but these cases have been very rarely reported. ${ }^{96}$ 
Transmission by organ transplantation is theoretically possible, but it has never been reported, as this is probably related to the reduced number of transplants carried out in disease endemic areas. ${ }^{97}$

- Possible transmission of the parasite through sexual contact has been described in a woman who never visited an endemic country and was never exposed to any other risk factors, but she did have a male partner with confirmed gambiense HAT. ${ }^{98}$

\section{Risk factors}

The risk factors for the transmission of this disease are determined by the increases in the possibility with which humans come into contact with a tsetse fly, and these factors are thus related to the site of contact between the tsetse fly and the human, and the intensity and frequency of this contact. In rhodesiense HAT, these risk factors are also related to the presence of nonhuman reservoirs.

\section{Gambiense human African trypanosomiasis}

The risk factors for gambiense HAT vary according to the different environmental settings and the characteristics of the vector in the different biotopes, and the activities carried out by human beings in the biotopes occupied by the tsetse flies.

- In humid forest, the tsetse flies are widely distributed, and human-fly contact is related to activities such as hunting, fetching firewood, timber-related activities, and forest clearing for farming. ${ }^{99}$

- In the woodland savanna and riverine forest galleries, the fly is found close to rivers and streams. The risk of transmission has been associated with activities that have been developed along these water bodies, such as fetching water, washing clothing or food (cassava), the artisanal extraction of palm oil, brewing, gold and diamond mining, and fishing. ${ }^{36,100,101}$ The risk of transmission increases when tsetse habitats are restricted, for example, during the dry season.

- In the transitional vegetation between forest and woodland savanna, the islands of vegetation provide a suitable habitat for tsetse, and these locations act as points from which hosts are sighted. These areas are often used for farming, making this activity a risk factor in these areas. ${ }^{101}$

- In the mangrove areas, tsetse flies find a favorable habitat where a high risk of transmission is associated with fishing and crustacean collection, but the parasite is also found in cleared areas used for rice cultivation. Pirogue jetties and fishing encampments are areas where humanfly contact can be intense. ${ }^{102,103}$

- Coca, coffee, and also mango and banana plantations, where the original forest has been replaced, are also suitable habitats for tsetse flies, and these areas are related to transmission in plantation workers. ${ }^{104}$

- Gambiense HAT is considered a rural disease, but transmission has also been occasionally observed in urban settings. Nevertheless, transmission in urban areas is associated with travels to neighboring rural areas for cultivating fields, or it may occur in suburban outskirts closer to transitional vegetation areas, where agricultural activities are possible; these areas constitute a suitable tsetse habitat with few alternative hosts. ${ }^{105,106}$

It has been described that certain protective immunity exists against new infections in humans after suffering from the disease. ${ }^{107,108}$

The risk associated with age- and sex-related factors pertains to the activities and behaviors made by the different age and sex groups. In general, gambiense HAT is predominately a disease of adults, mainly affecting young adults, as this is the group that is most involved in productive activities that facilitate contact with the vector. ${ }^{28,77,101}$ Children are usually less affected than adults, but in some areas (such as mangroves), teens present a higher rate of infection related to fishing and leisure activities in water areas. ${ }^{109,110}$ In areas where at-risk activities include mining, hunting, or fishing, the prevalence is higher in males. In transitional vegetation areas where the risk of infection is associated with agriculture and domestic activities at bodies of water, similar prevalence rates have been found in males and females. ${ }^{28,77,101,110}$

The clustering of cases and some familial aggregation has been described, as the risk of gambiense HAT for a child significantly increased when the mother also had HAT. ${ }^{28}$ It has been suggested that familial clustering was a consequence of similar exposure to the vector and shared behavioral risk factors, rather than of genetic susceptibility. ${ }^{111,112}$

The risk of gambiense HAT infection in short-term travelers from nonendemic areas is very low, as tourists rarely visit the rural areas where gambiense HAT is endemic. Gambiense HAT cases that are occasionally diagnosed in nonendemic countries are mainly seen in immigrants and expatriate residents living in at risk areas for extended periods. ${ }^{11}$

\section{Rhodesiense human African trypanosomiasis}

The two different settings described for rhodesiense HAT mean different situations of risk for contracting the disease. 
- In the areas where wildlife is the main reservoir, the main risk factors are associated with entry into areas that are usually restricted and where wildlife is preserved (national parks and game reserves). A high density of tsetse flies in these areas increases this risk. Exposure is related to the movement of humans, animals, and tsetse flies out of or into reserves, especially during specific seasons of the year. Populations living in the periphery of game reserves and national parks are the ones at the highest risk. ${ }^{113}$ The exposure to rhodesiense HAT in this area involves wildlife conservation activities (for example, rangers and park wardens), hunting and poaching, fishing, honey and firewood collection, and visitors of national parks (tourists). ${ }^{1,11,28,113,114}$ The movement of livestock for grazing in these areas is another risk factor for herdsmen; ${ }^{115}$ there is also the potential that this risk could be transferred to other areas where the cattle is moving.

- In the areas where livestock is the main reservoir, activities linked to cattle raising increase this risk, but the general population living in these areas is also exposed. Those living on the periphery of villages or near the cattle markets are most at risk. ${ }^{114}$

With respect to age, those at highest risk for rhodesiense HAT are in the working-age group, which is comprised of individuals venturing into tsetse habitats. ${ }^{114}$ It is assumed that their contact with flies occurs when the humans enter into the woodland habitat of the flies, but recent studies have found the frequent peridomestic presence of some tsetse species, and even tsetse biting humans inside buildings, ${ }^{116}$ but transmission still mainly occurs in more tsetse-suitable habitats. As is the case in gambiense HAT, the sex-based risks are related to the specific activities and behaviors engaged upon by the members of each sex; in general, rhodesiense HAT is predominately a disease of males. ${ }^{28,114,117,118}$ Familial aggregation also occurs in rhodesiense HAT, ${ }^{114,117}$ which is most likely related to the common exposure of vectors, especially since there are shared behavioral and spatial risk factors among members of a household.

Given that rhodesiense HAT is an acute disease, it is possible to observe a certain seasonal variation in transmission that is linked to the density of Glossina: The peak in the Glossina population densities is usually seen after the rainy season, and the peak in the human cases can be detected in 1-3 months after the rainy season. ${ }^{119}$

The risk of acquiring rhodesiense HAT for short-term travelers from nonendemic areas is low, but this risk factor is more important than that of developing gambiense HAT, as tourists commonly visit natural areas where rhodesiense
HAT is transmitted. ${ }^{11}$ Cases of rhodesiense HAT in travelers can occasionally appear in clusters of people who have visited common areas. ${ }^{120}$

\section{Burden and social impact}

HAT occurs mainly in remote rural areas of sub-Saharan Africa, where suitable environmental conditions for the vector's presence occur. Populations living in these areas have a low income level and they are often neglected. ${ }^{121}$

The disease is considered to have a case fatality rate close to $100 \% .^{1,2}$ Nevertheless, some older reports and recent studies have shown an alternative natural progression of HAT to asymptomatic carriers, or even to the apparent spontaneous resolution of the infection. ${ }^{7}$ Apart from the lethality and the individual-level impact, since the disease affects mainly individuals of productive age, and given that it is mainly a chronic disease, it affects the income-generating capacity of families, worsening the economic situation of impoverished groups. The cost of patient care and the necessity of seeking medical services to look for a diagnosis and treatment mean that there is an added and important cost when the generation of resources in the family is threatened. ${ }^{122}$ In this way, the disease contributes to maintain the poverty cycle in these neglected communities.

In endemic areas, people know of HAT infection and fear it because of the long lasting suffering and the lethality of the disease. ${ }^{123}$ HAT is also a stigmatizing disease, mainly because of the neuropsychological impairment entailed, and in many endemic areas, the presence of the disease is hidden and the patients are discriminated or abandoned. ${ }^{79,123}$

\section{Incidence of the disease and time trends}

Sleeping sickness was first described around the 14th century, but it has been considered as endemic in African regions since the appearance of human beings. ${ }^{124}$ At the beginning of the 20th century, epidemics of sleeping sickness in the Lake Victoria region, Congo River basin, and other areas of central Africa decimated the population. ${ }^{124-126}$ These epidemics were mainly linked to increased population movements and changes in the environment (for example, deforestation or the introduction of intensive agriculture for cash crops), both of which are factors that are related to the new colonial order. ${ }^{125}$ It was at that moment when the parasite causing the disease was identified, and the link with the tsetse fly as vector was established. ${ }^{126}$ 
Concerned by the socioeconomic problems caused by HAT, colonial authorities set up successful control measures, ${ }^{126}$ which progressively controlled the disease, reaching a very low, generalized transmission by the mid-1960s, with a minimum of 4,435 cases declared in Africa in 1964 (Figure 1). ${ }^{127}$ This led to the feeling that the disease was tackled and would soon be eliminated, despite the fact that there was not a clear objective of elimination, and a subsequent surveillance system was established. ${ }^{128}$ In the following years, coinciding with the independence process in the majority of African countries, the expenditures for HAT were reduced, and awareness and surveillance of the disease decreased. Together with the presence of social instability, the conflicts and insecurity that constrained the disease control interventions led the disease to resurge in the 1980s and 1990s, ${ }^{129-131}$ and the number of cases reported reached worrisome levels, considering also that only a fraction of the areas at risk were under surveillance. At that time, the total number of existing cases of HAT was estimated at 300,000 cases. ${ }^{35}$

The situation of HAT at that time received attention from the health authorities in endemic countries and bilateral and multilateral agencies. ${ }^{128}$ The World Health Organization (WHO) responded to this situation by coordinating international partners working in HAT control, raising awareness and political will, and bringing new resources from the public and private sectors to support national control programs. ${ }^{128}$ Control programs were reinforced and, as a result, since 2000 , the number of notified cases has shown a steady decrease, falling since 2009 to below 10,000 new reported cases (Figure 1). ${ }^{128}$

\section{Gambiense human African trypanosomiasis}

As for rhodesiense HAT, gambiense HAT can appear in epidemic forms, as has happened in the past, ${ }^{132}$ with major epidemics noted at the end of the 19th century and at the beginning of the 20th century (1896-1906), ${ }^{3,133}$ in the 1920s and $1930 \mathrm{~s},{ }^{132,133}$ and in the 1980s and 1990s. ${ }^{129-131}$ The origin of these epidemics is linked to sociopolitical changes and conflicts that have resulted in sudden modifications of the environment, displacement of populations, changes in human practices, and feeble or absent HAT control programs in a weak health care system environment. ${ }^{129-131}$

The increase of gambiense HAT cases in the first third of the 20th century, which reached, in some cases, epidemic levels, generated a response from colonial governments that were initially based on the application of vector control measures, and later on the deployment of mobile teams that visited the villages in the at-risk areas to conduct systematic screening of the entire population and to treat the detected cases. ${ }^{129-131}$ This strategy was successful and systematically applied for more than three decades, reaching complete control of the diseases in the early 1960s. At that moment, HAT control activities declined and this was associated with the conflict and sociopolitical instability in most of the gambiense HAT endemic countries (Angola, Democratic Republic of Congo,

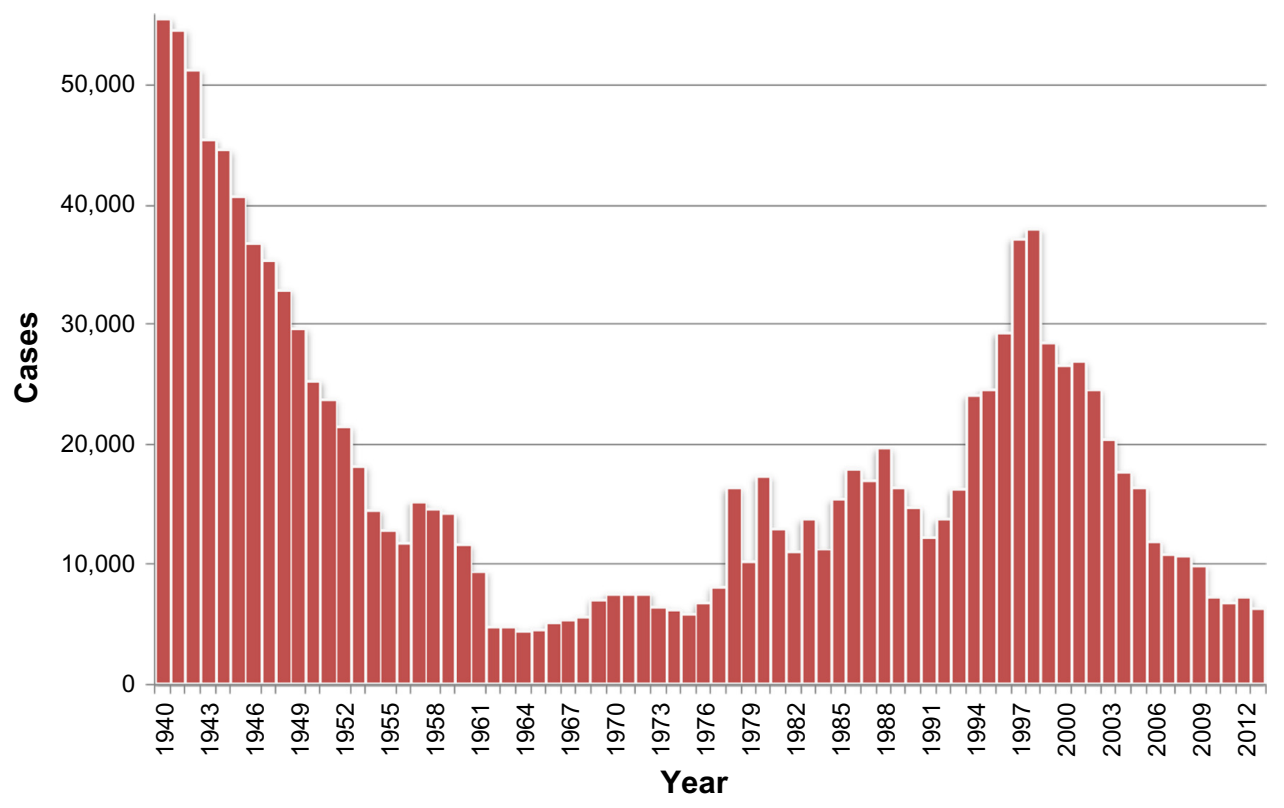

Figure I Total number of new cases of human African trypanosomiasis reported to the World Health Organization, I940-20I3.

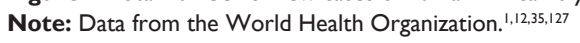


South Sudan, Central African Republic, Uganda); this led to the resurgence of the infection in the 1980s. ${ }^{129-131}$

The renewed technical and logistic support for countrybased programs at the beginning of the 21 st century allowed for the reinforcement of active and passive case detection, thus increasing the number of people screened, to enhance drug availability and access to treatment, as well as to improve epidemiological knowledge of the disease. ${ }^{128,134}$ The result was the improvement of the control of the disease and, therefore, a substantial progressive decrease in the annual number of cases reported, reaching 6,228 new cases that were declared in 2013 (Table 1). 1,128,134,135

In the last 5 years (2009-2013), gambiense HAT cases have represented $98 \%$ of the total proportion of HAT cases; the cases of rhodesiense HAT have accounted for the remaining $2 \%$. ${ }^{1,128,135}$

The trend in cases reported of gambiense HAT showed a decrease in the prevalence of the disease of $76 \%$ since 2000 , with a number of around 7,000 cases reported in the last 3 years. ${ }^{1,128,135}$ Nevertheless, HAT mainly affects remote rural communities where the health infrastructure is basic; furthermore, there are other endemic areas where accessibility is complicated because of security problems or topography constraints. Therefore, a certain number of cases are not recognized and diagnosed. ${ }^{1,128,134-136}$ Despite the fact that epidemiological knowledge about the disease has improved considerably in the past decade, there is still a gap between the number of cases declared and the number of actual cases. Currently, it is estimated that the annual incidence of gambiense HAT is less than 20,000 cases. ${ }^{1,128,134}$

\section{Rhodesiense human African trypanosomiasis}

Rhodesiense HAT can occur in both endemic and epidemic forms. The usual situation is that the disease occurs in an endemic state, with sporadic human cases. In areas with wildlife as the main reservoir, human cases appear occasionally, even when there are periods of several years without cases. ${ }^{1,115,134,137}$ In areas with livestock as the main reservoir, the cases usually occur more regularly. ${ }^{138,139}$ In both situations, human cases can be absent, although the parasite is still detectable in domestic reservoirs. ${ }^{87}$

Epidemics have been frequently linked to social or environmental disruptions that compel people and livestock to move to

Table I Total number of new cases of gambiense human African trypanosomiasis reported to the World Health Organization from 2000-2013

\begin{tabular}{|c|c|c|c|c|c|c|c|c|c|c|c|c|c|c|}
\hline & 2000 & 2001 & 2002 & 2003 & 2004 & 2005 & 2006 & 2007 & 2008 & 2009 & 2010 & 2011 & 2012 & 2013 \\
\hline Angola & 4,546 & 4,577 & 3,621 & 3,115 & 2,280 & $\mathrm{I}, 727$ & 1,105 & 648 & 517 & 247 & 211 & 154 & 70 & 69 \\
\hline Benin & 0 & 0 & 0 & 0 & 0 & 0 & 0 & 0 & 0 & 0 & 0 & 0 & 0 & 0 \\
\hline Burkina Faso & 0 & 0 & 0 & 0 & 0 & 0 & 0 & 0 & 0 & 0 & 0 & 0 & 0 & 0 \\
\hline Cameroon & 27 & 14 & 32 & 33 & 17 & 3 & 15 & 7 & 13 & 24 & 16 & 15 & 7 & 6 \\
\hline Chad & 153 & 138 & 715 & 222 & 483 & 190 & 276 & 97 & 196 & 510 & 232 & 276 & 197 & 193 \\
\hline Central African & 988 & 718 & 572 & 539 & 738 & 666 & 460 & 654 & 1,194 & $\mathrm{I}, 054$ & 395 & 132 & 381 & 62 \\
\hline \multicolumn{15}{|l|}{ Republic } \\
\hline Congo & 111 & 894 & 1,005 & 717 & 873 & 398 & 300 & 189 & 182 & 87 & 87 & 61 & 39 & 20 \\
\hline Côte d'lvoire & 188 & 92 & 97 & 68 & 74 & 42 & 29 & 13 & 14 & 8 & 8 & 10 & 9 & 7 \\
\hline $\begin{array}{l}\text { Democratic Republic } \\
\text { of the Congo }\end{array}$ & 16,975 & 17,322 & 13,853 & | I,48| & 10,369 & 10,269 & 8,023 & 8,162 & 7,326 & 7,183 & 5,629 & 5,595 & 5,983 & 5,647 \\
\hline Equatorial Guinea & 16 & 17 & 32 & 23 & 22 & 17 & 13 & 15 & II & 7 & 8 & 1 & 2 & 3 \\
\hline Gabon & 45 & 30 & 26 & 26 & 49 & 53 & 31 & 30 & 24 & 14 & 22 & 17 & 9 & 16 \\
\hline Gambia & - & - & - & - & - & - & - & - & - & - & - & - & - & - \\
\hline Ghana & 1 & 0 & 0 & 0 & 0 & 0 & 0 & 0 & 0 & 0 & 0 & 0 & 0 & I \\
\hline Guinea & 52 & 72 & 132 & 130 & 95 & 94 & 48 & 69 & 90 & 79 & 68 & 57 & 70 & 78 \\
\hline Guinea Bissau & - & - & - & - & - & - & - & - & - & - & - & - & - & - \\
\hline Liberia & - & - & - & - & - & - & - & - & - & - & - & - & - & - \\
\hline Mali & 0 & 0 & 0 & 0 & 0 & 0 & 0 & 0 & 0 & 0 & 0 & 0 & 0 & 0 \\
\hline Niger & - & - & - & - & - & - & - & - & - & - & - & - & - & - \\
\hline Nigeria & 14 & 14 & 26 & 31 & 10 & 21 & 3 & 0 & 0 & 0 & 2 & 3 & 2 & 0 \\
\hline Senegal & - & - & - & - & - & - & - & - & - & - & - & - & - & - \\
\hline Sierra Leone & - & - & - & - & - & - & - & - & - & - & 0 & - & - & - \\
\hline South Sudan & $|, 80|$ & 1,919 & 3,121 & 3,061 & I,742 & $\mathrm{I}, 853$ & 789 & 469 & 623 & 373 & 199 & 272 & 317 & 117 \\
\hline Togo & 0 & 0 & 0 & 0 & 0 & 0 & 0 & 0 & 0 & 0 & 0 & 0 & 0 & 0 \\
\hline Uganda & 948 & 310 & 604 & 517 & 378 & 311 & 290 & 120 & 198 & 99 & 101 & 44 & 20 & 9 \\
\hline Total reported & 25,865 & 26,117 & 23,836 & 19,963 & 17,130 & 15,644 & I I,382 & 10,473 & 10,388 & 9,685 & 6,978 & 6,637 & 7,106 & 6,228 \\
\hline
\end{tabular}


marginal lands where the contact with tsetse flies increases and can trigger local outbreaks of the disease, ${ }^{85,120,137,140-142}$ which is what probably occurred in the huge Busoga epidemic that took place in Uganda in the early 1990s. ${ }^{5}$ Large-scale movement of livestock related to economic factors can extend the rhodesiense HAT foci, or even introduce the disease in new areas. ${ }^{143}$

As in gambiense HAT, since the beginning of the $21 \mathrm{st}$ century, there has been a clear decreasing trend in the number of cases reported by endemic countries (Table 2). 1,134,135 Environmental changes related to land use and population density have reduced the habitats for wildlife and these factors, therefore, have contributed to this decreasing trend.

Uganda is the only country in sub-Saharan Africa presenting both rhodesiense and gambiense HAT. ${ }^{1,6}$ The risk of the geographical overlap of both forms, as related to movements of the livestock reservoir to areas of gambiense HAT, has been described. ${ }^{6}$ This possibility could have important therapeutic and diagnostic implications. Refugees from endemic areas of gambiense HAT in the Democratic Republic of the Congo are also moving to endemic areas of rhodesiense HAT in western Tanzania, creating opportunities for a possible overlap of the two forms of HAT. ${ }^{1,144}$

\section{Geographical distribution (focus)}

HAT is a focal disease; this means that the distribution of the disease is patchy, being limited to a circumscribed area, called a "focus", beyond which the disease does not occur. ${ }^{145}$ The focus was qualitatively defined by the WHO Expert Committee in 1986 as "a zone of transmission to which a geographical name is given (locality, region or river)". ${ }^{12}$ In these areas, the environment is adequate for the host, the reservoir, the vector, and the parasite and, subsequently, transmission can occur. The foci usually tend to be stable over time, with geographical limits slightly expanding or diminishing. However, environmental changes or human or livestock population movements can cause variations in intensity of transmission, or even changes in geographical settings. ${ }^{77}$

There are around 360 HAT foci that have been described currently, all of which are circumscribed to 36 sub-Saharan Africa countries and are mainly located in rural and remote environments. ${ }^{1,12,35,146-148}$

The Atlas of Human African Trypanosomiasis is a WHO-led initiative that was jointly developed with the Food and Agriculture Organization of the United Nations, and with disease endemic countries in the framework of the Program against African Trypanosomosis. ${ }^{147,149}$ This Atlas geographically locates, at the village of residence level, all the cases of HAT reported since 2000 . The Atlas is a dynamic tool, and it is regularly improved and updated in terms of accuracy and completeness (Figure 2). ${ }^{149}$

\section{Gambiense human African trypanosomiasis}

Currently, there are around 300 gambiense HAT foci that have been described, all of which are circumscribed to 24 sub-Saharan Africa countries (Angola, Benin, Burkina Faso, Cameroon, Chad, Central African Republic, Congo, Côte d'Ivoire, Democratic Republic of the Congo, Equatorial Guinea, Gabon, Gambia, Ghana, Guinea, Guinea Bissau, Liberia, Mali, Niger, Nigeria, Senegal, Sierra Leone, South Sudan, Togo, Uganda). ${ }^{146}$ A detailed map of these foci is provided on the WHO web page. ${ }^{148}$ These foci can be classified into three groups, according to the reported intensity of disease transmission. ${ }^{135,149}$

Table 2 Number of new cases of rhodesiense human African trypanosomiasis reported to the World Health Organization (2000-20I3)

\begin{tabular}{|c|c|c|c|c|c|c|c|c|c|c|c|c|c|c|}
\hline & 2000 & 2001 & 2002 & 2003 & 2004 & 2005 & 2006 & 2007 & 2008 & 2009 & 2010 & 2011 & 2012 & 2013 \\
\hline Botswana & - & - & - & - & - & - & - & - & - & - & - & - & - & - \\
\hline Burundi & - & - & - & - & - & - & - & - & - & - & - & - & - & - \\
\hline Ethiopia & - & - & - & - & - & - & - & - & - & - & - & - & - & - \\
\hline Kenya & 15 & 10 & 11 & 0 & 0 & 0 & 1 & 0 & 0 & 1 & 0 & 0 & 2 & 0 \\
\hline Malawi & 35 & 38 & 43 & 70 & 48 & $4 I$ & 58 & 50 & 49 & 39 & 29 & 23 & 18 & 35 \\
\hline Mozambique & - & - & 1 & - & I & - & - & - & - & - & - & - & - & - \\
\hline Namibia & - & - & - & - & - & - & - & - & - & - & - & - & - & - \\
\hline Rwanda & - & - & - & - & - & - & - & - & - & - & - & - & - & - \\
\hline Swaziland & - & - & - & - & - & - & - & - & - & - & - & - & - & - \\
\hline Tanzania & 350 & 277 & 228 & 113 & 159 & 186 & 127 & 126 & 59 & 14 & 5 & 1 & 4 & 1 \\
\hline Uganda & 300 & 426 & 329 & 338 & 335 & 473 & 261 & 119 & 138 & 129 & 112 & 82 & 71 & 43 \\
\hline Zambia & 9 & 4 & 5 & 15 & 9 & 7 & 6 & 10 & 13 & 4 & 8 & 3 & 6 & 6 \\
\hline Zimbabwe & - & - & - & - & - & - & - & - & 0 & 3 & 2 & 4 & 9 & 1 \\
\hline Total reported & 709 & 755 & 617 & 536 & 552 & 710 & 453 & 305 & 259 & 190 & 156 & 113 & 110 & 86 \\
\hline
\end{tabular}




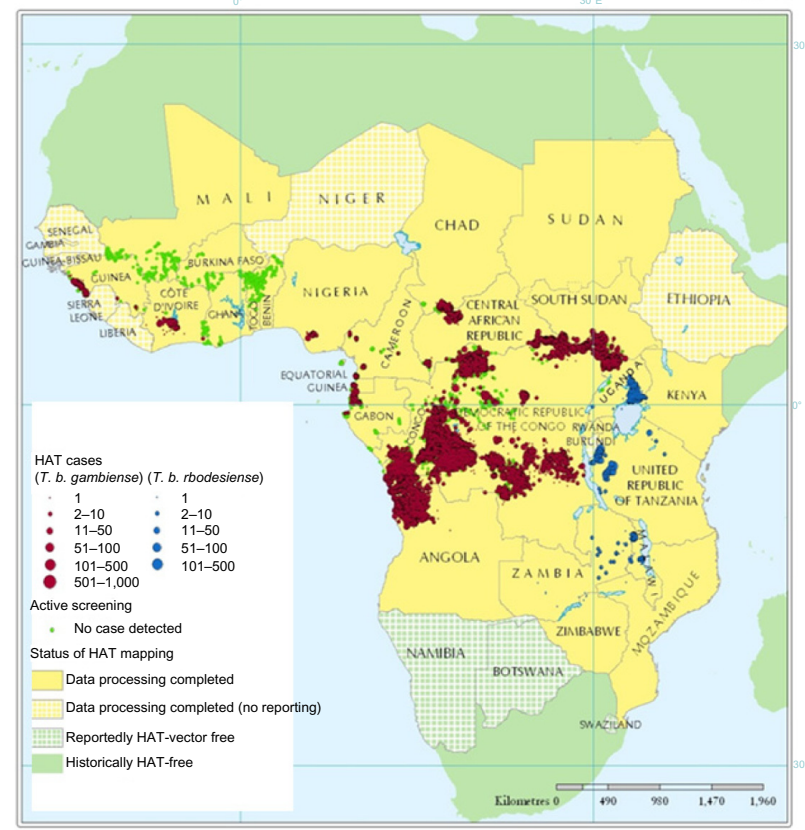

Figure 2 Geographic distribution of HAT cases reported from 2000-2009. Note: Adapted from Simarro PP, Cecchi G, Paone M, et al. The Atlas of human African trypanosomiasis: a contribution to global mapping of neglected tropical diseases. Int J Health Geogr. 2010;9:57. ${ }^{144}$

Abbreviations: HAT, human African trypanosomiasis; T. b., Trypanosoma brucei.

1. Foci at high to very high levels of transmission. These are defined as those areas where the average annual number of cases reported is at least one per 1,000 inhabitants during the past 5 years.

2. Foci at moderate levels of transmission. These are those where at least one case per 10,000 inhabitants (but less than one per 1,000 inhabitants) has been reported yearly during the past 5 years.

3. Foci at low to very low levels of transmission. These are those where at least one case per 1,000,000 inhabitants per annum (but less than one case per 10,000 inhabitants) has been observed during the past 5 years.

There are also some areas where transmission intensity is not well known because it is difficult to access these areas due to terrain or security constraints, or due to the lack of an effective surveillance system.

The prevalence rates in active case finding surveys are usually between $1 \%$ and $5 \%$ in areas where transmission levels are high or very high, reaching values over $10 \%$ in some extreme cases. ${ }^{28}$ The prevalence rate during the first screening in high transmission areas where no control activities have been carried out over the course of several years is higher, as it reflects the cases that have accumulated during that period. Usually, prevalence rates decrease sharply during the subsequent rounds of active screening when the coverage is high. ${ }^{1,28,79,83}$
In the period from 2009-2013, 82\% of gambiense HAT cases were reported from the Democratic Republic of the Congo, 5.5\% from the Central African Republic, $4 \%$ from Chad, 3.5\% from South Sudan, 2\% from Angola, and the remaining 3\% from another eight countries (Cameroon, Congo, Cote d'Ivoire, Equatorial Guinea, Gabon, Guinea, Nigeria, and Uganda). ${ }^{1,149}$

\section{Rhodesiense human African trypanosomiasis}

There are around 60 historical foci of rhodesiense HAT in 13 African countries (Botswana, Burundi, Ethiopia, Kenya, Malawi, Mozambique, Namibia, Rwanda, Swaziland, Tanzania, Uganda, Zambia, and Zimbabwe). A detailed map of these foci is provided on the WHO web page. ${ }^{148}$ These foci can be classified according to the pattern of transmission related to the reservoir: ${ }^{135}$

1. Foci where wild animals, mainly kept in protected areas, are the main parasite reservoir. This happens around natural protected areas in southwestern Uganda, western and northern Tanzania, southern Kenya, Zambia, Malawi, and northern Zimbabwe. ${ }^{135}$

2. Foci where the main parasite reservoir is cattle. This situation is found in southeastern Uganda and western Kenya. ${ }^{135}$

In some areas, both patterns coexist with a mixed transmission pattern, where the reservoir can either be wild animals or cattle; this is observed in western Tanzania.

In the last 5 years (2009-2013), 67\% of the cases reported happened in Uganda, $22 \%$ in Malawi, and $4 \%$ in the United Republic of Tanzania, and 4\% in Zambia. Sporadic cases have been declared in Zimbabwe and Kenya., 149

\section{At-risk population}

The risk of disease transmission is basically limited to the foci of the disease and cannot be generalized on a national or continental scale. Based on new spatial analysis of the data included in the WHO Atlas of HAT and global population distribution layers (LandScan ${ }^{\mathrm{TM}}$; Oak Ridge National Laboratory, Oak Ridge, TN, USA), the extension and the location of different levels of risk has been estimated. ${ }^{149}$ Therefore, it has been estimated that 70 million people live at different levels of risk for HAT infection. Moreover, 57 million (81\%) people distributed over an area of approximately 1.38 million $\mathrm{km}^{2}$ are at risk of gambiense HAT; this population is distributed in 14 of the 24 countries listed as endemic for gambiense HAT. ${ }^{149}$ Furthermore, 12.3 million people are at risk of contracting rhodesiense HAT, and they are distributed over an area of 0.171 million $\mathrm{km}^{2} .{ }^{149}$ More 
than 5 million people live in areas classified as high or very high risk for contracting HAT. ${ }^{149}$

The Democratic Republic of the Congo has the greatest number of people at risk (36 million) for HAT, and the largest risk area $\left(790,000 \mathrm{~km}^{2}\right)$, but South Sudan and Angola also have sizeable at-risk populations. ${ }^{149}$ In West Africa, the most endemic areas are classified as moderate risk and they are located in the central Côte d'Ivoire and coastal Guinea (Figure 3 and Table 3). ${ }^{149}$

\section{The future of the disease: elimination and global environmental change}

The control and surveillance activities carried out over the last 15 years have been successful, as shown by the decreasing trend of HAT cases. Considering the current state of control of the disease, but also the epidemiological vulnerability of the disease, the availability of effective strategies and tools, and the international commitment and political will, the elimination of the disease has been considered as feasible. ${ }^{128}$ In fact in 2012, the WHO targeted the elimination of gambiense HAT as a public health problem by $2020 .{ }^{150}$ The final goal in the future should be the sustainable elimination of the disease, defined as the interruption

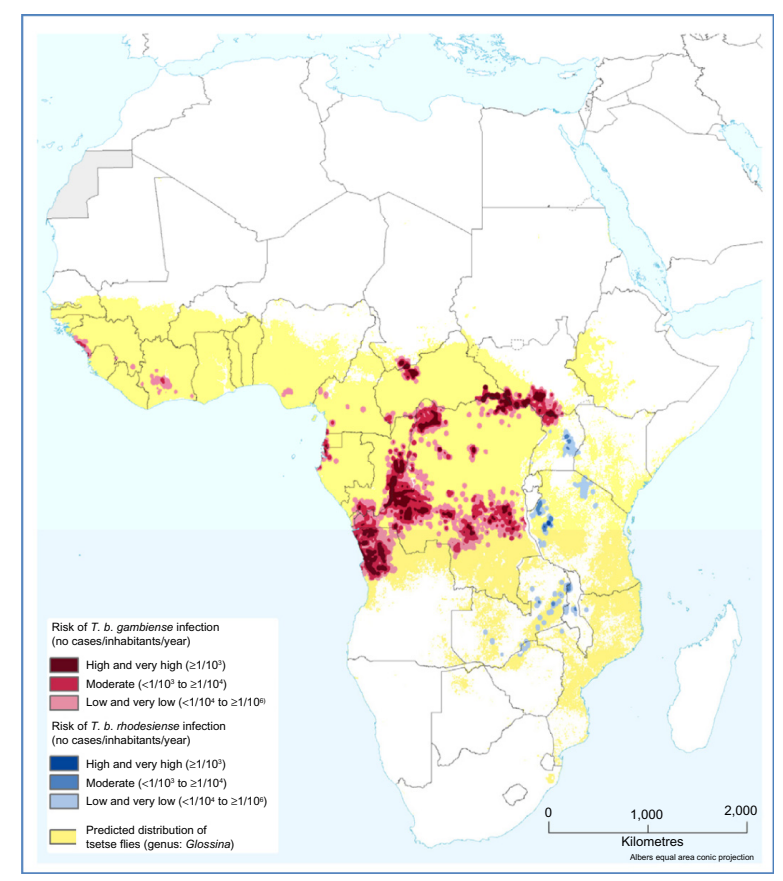

Figure 3 Population at risk of HAT.

Note: Adapted from Simarro PP, Cecchi G, Franco JR, et al. Estimating and mapping the population at risk of sleeping sickness. PLoS Negl Trop Dis. 20I2;6(I0):el 859. ${ }^{149}$ Abbreviations: T. b., Trypanosoma brucei; HAT, human African trypanosomiasis. of the transmission of gambiense HAT, which has been targeted for $2030 .{ }^{146}$

To introduce the feasible goal of elimination, highlighting the achievements made and the adequate momentum to reach a public health milestone could avoid the lack of interest and the oblivion in the health decisions and plans of HAT, a localized disease with reduced number of cases. Keeping a clear and well-defined elimination goal could help to maintain awareness and to invest the needed resources to continue the control of the disease, preventing the possible reemergence of HAT in the coming future.

In this context, the integration of gambiense HAT control and surveillance activities in the health care system is crucial to ensure the sustainability of the elimination. Nevertheless, in the rural areas where HAT is prevalent, the peripheral health care system is often weak, understaffed, and underequipped, with a low coverage or low attendance rate. ${ }^{151}$ Therefore, the reinforcement and population awareness and the empowerment of the health system to implement the activities included in the elimination strategies is essential. ${ }^{128}$ More user-friendly diagnostic and treatment tools will facilitate this integration, and operational research needs to address the improvement of control tools.

Previous experience has shown that HAT elimination is not an easy task, and will demand important effort, time, and resources. ${ }^{128}$ Adequate funding is needed to implement activities and to support research to provide the tools that will make elimination sustainable. A continued long-term commitment by donors is needed. The ownership of the process of elimination by endemic countries is a decisive element, and sociopolitical stability and security are required to apply the strategies for elimination. ${ }^{128}$

On the other hand, since rhodesiense HAT is a zoonosis where the animal reservoir plays a key role, its elimination (the total interruption of disease transmission) is not regarded as feasible. ${ }^{1,128}$ Nevertheless, the possibility of its elimination has been considered as a public health problem. ${ }^{150}$ An integrated approach, involving both the veterinary medicine services and wildlife sectors, is needed.

On the road to HAT elimination, some gaps in the epidemiological knowledge of the disease need to be filled. There still exist gray areas where epidemiological knowledge about the presence and distribution of the disease is limited and needs to be clarified. Adequate and sensitive tools and strategies are needed to assess these areas, and to fill the gaps in the map. In the same way, indicators and modeling tools for estimating the location and abundance of undetected cases will be very useful. 
Table 3 Population at risk by country

\begin{tabular}{|c|c|c|c|c|}
\hline Country & $\begin{array}{l}\text { Population at high } \\
\text { and very high risk }\left(\times 10^{3}\right)\end{array}$ & $\begin{array}{l}\text { Population at } \\
\text { moderate risk }\left(\times 10^{3}\right)\end{array}$ & $\begin{array}{l}\text { Population at low and } \\
\text { very low risk }\left(\times 10^{3}\right)\end{array}$ & Total $\left(\times 10^{3}\right)$ \\
\hline \multicolumn{5}{|l|}{ Gambiense HAT } \\
\hline Angola & 740 & 749 & 3,278 & 4,767 \\
\hline Cameroon & & 28 & 603 & 631 \\
\hline Central African Republic & 69 & 130 & 237 & 435 \\
\hline Chad & 109 & 114 & 242 & 465 \\
\hline Congo & 113 & 451 & 2,002 & 2,566 \\
\hline Cotê d'Ivoire & & 230 & 2,442 & 2,672 \\
\hline Democratic Republic of the & 3,569 & 10,767 & 21,911 & 36,247 \\
\hline \multicolumn{5}{|l|}{ Congo } \\
\hline Equatorial Guinea & 2 & 27 & 15 & 43 \\
\hline Gabon & 2 & 21 & 780 & 803 \\
\hline Guinea & & 187 & 2,420 & 2,606 \\
\hline Nigeria & & & 2,183 & 2,183 \\
\hline Sierra Leone & & 1 & 170 & 170 \\
\hline South Sudan & 416 & 453 & 401 & 1,270 \\
\hline Uganda & 142 & 1,275 & 707 & 2,124 \\
\hline Total gambiense HAT & 5,162 & $|4,43|$ & 37,390 & 56,983 \\
\hline \multicolumn{5}{|l|}{ Rhodesiense HAT } \\
\hline Burundi & & & 38 & 38 \\
\hline Kenya & & & $\mathrm{I}, 124$ & 1,124 \\
\hline Malawi & & 194 & 716 & 910 \\
\hline Mozambique & & & 58 & 58 \\
\hline United Republic of Tanzania & 22 & 373 & 1,429 & $\mathrm{I}, 824$ \\
\hline Uganda & & 847 & 7,029 & 7,877 \\
\hline Zambia & & 14 & 402 & 416 \\
\hline Zimbabwe & & & 94 & 94 \\
\hline Total rhodesiense HAT & 22 & 1,429 & 10,890 & $|2,34|$ \\
\hline Total & 5,184 & 15,860 & 48,280 & 69,324 \\
\hline
\end{tabular}

Notes: Adapted from Simarro PP, Cecchi G, Franco JR, et al. Estimating and mapping the population at risk of sleeping sickness. PLoS Negl Trop Dis. 2012;6(10):el859.149 Abbreviation: HAT, human African trypanosomiasis.

In the case of gambiense HAT, the epidemiological importance of animal reservoirs and healthy human carriers in the persistence of disease transmission needs to be elucidated. The possibility of a sylvatic cycle of gambiense HAT, which contributes to the persistence of the disease, has to be studied. Risk factors for HAT reintroduction in areas where the disease has been eliminated also need to be considered. A better understanding of the vectorial capacity of the tsetse fly to transmit the disease and of the vector-host interaction could help improve the vector control strategies.

Population growth and climate change will be important factors that could affect the geographic distribution of HAT. Major environmental changes are forecast in many parts of Africa in the coming decades. ${ }^{152,153}$ The population growth and the consequent increment of human density in some areas is bringing about a change in land use, with degradation of vegetation often noted, which impacts fly distribution, reduces the fly's density, or even eliminates the fly. ${ }^{154-156}$ Only some species of tsetse flies (for example, G. p. gambiense) can coexist with relatively high human densities, ${ }^{155}$ and the reduction of other alternative food sources can increase the contact between humans and the fly. The intense urbanization process observed in Africa has led to the periurban foci of gambiense HAT. ${ }^{36,105,106,157}$

Environmental or social factors can trigger changes in the intensity of transmission and, therefore, can result in outbreaks or epidemics that are characterized by an increase in the number of cases, and sometimes by the expansion of the area of focus, or by the spreading of the disease to new areas. ${ }^{158,159}$ On the other hand, increase in the numbers of visitors to wildlife zones, as well as political and economic migrations of the African population to the north, could result in HAT cases that are more frequently reported in nonendemic countries. ${ }^{11}$

A rise in temperature may result in the invasion of currently nonendemic geographic areas by tsetse flies, or even in disappearance of the flies in currently infested areas. There have been some attempts to predict the future distribution 
of tsetse flies and HAT according to climate changes, ${ }^{160}$ but these attempts are limited by the lack of robust data. Drought may worsen landscape degradation, as is happening in West Africa where the northernmost limit of the fly's distribution moved $200 \mathrm{~km}$ southward due to population growth and drought. ${ }^{156}$ In this sense, recent studies show that in Burkina Faso, tsetse areas have been reduced by $70,000 \mathrm{~km}^{2}$ since 1949, and historical HAT foci have disappeared. ${ }^{156}$ It is clear that the impact of population growth and climate change will differ according to region, and more accurate estimates of population growth and improved climate simulations at a more local level will be needed to forecast the future risks of the disease's distribution.

\section{Acknowledgments}

The authors would like to thank the members of the WHO Expert Advisory Panel on Trypanosomiasis for their participation in fruitful discussions, which have been considered for this paper. Special acknowledgment to Jose Antonio Ruiz-Postigo for the critical reading of the document.

\section{Disclosure}

The boundaries and names shown and the designations used on the maps presented in this paper do not imply the expression of any opinion whatsoever on the part of the WHO concerning the legal status of any country, territory, city, or area or of its authorities, or concerning the delimitation of its frontiers or boundaries.

The views expressed in this paper are those of the authors and do not necessarily reflect the views of WHO. The authors report no other conflicts of interest in this work.

\section{References}

1. World Health Organization. Control and Surveillance of Human African Trypanosomiasis. Report of a WHO Expert Committee. WHO Technical Report Series 984. Geneva, Switzerland: World Health Organization; 2013.

2. Brun R, Blum J, Chappuis F, Burri C. Human African trypanosomiasis. Lancet. 2010;375(9709):148-159.

3. Koerner T, De Raadt P, Maudlin I. The 1901 Uganda sleeping sickness epidemic revisited: a case of mistaken identity? Parasitol Today. 1995;11(8):303-306.

4. Fèvre EM, Coleman PG, Welburn SC, Maudlin I. Reanalyzing the 1900-1920 sleeping sickness epidemic in Uganda. Emerg Infect Dis. 2004;10(4):567-573.

5. Hide G. History of sleeping sickness in East Africa. Clin Microbiol Rev. 1999;12(1):112-125.

6. Picozzi K, Fèvre EM, Odiit M, et al. Sleeping sickness in Uganda: a thin line between two fatal diseases. BMJ. 2005;331(7527):1238-1241.

7. Jamonneau V, Ilboudo H, Kaboré J, et al. Untreated human infections by Trypanosoma brucei gambiense are not $100 \%$ fatal. PLoS Negl Trop Dis. 2012;6(6):e1691.

8. Odiit M, Kansiime F, Enyaru JC. Duration of symptoms and case fatality of sleeping sickness caused by Trypanosoma brucei rhodesiense in Tororo, Uganda. East Afr Med J. 1997;74(12):792-795.
9. Checchi F, Filipe JA, Haydon DT, Chandramohan D, Chappuis F. Estimates of the duration of the early and late stage of gambiense sleeping sickness. BMC Infect Dis. 2008;8:16.

10. Sahlas DJ, MacLean JD, Janevski J, Detsky AS. Clinical problemsolving. Out of Africa. N Engl J Med. 2002;347(10):749-753.

11. Simarro PP, Franco JR, Cecchi G, et al. Human African trypanosomiasis in non-endemic countries (2000-2010). J Travel Med. 2012;19(1):44-53.

12. World Health Organization. Epidemiology and Control of African Trypanosomiasis. Report of a WHO Expert Committee. Technical Report Series 739. Geneva, Switzerland: World Health Organization; 1986.

13. Uilenberg G. A Field Guide for the Diagnosis, Treatment and Prevention of African animal Trypanosomosis. Rome, Italy: Food and Agriculture Organization of the United Nations: 1998.

14. Radwanska M, Chamekh M, Vanhamme L, et al. The serum resistanceassociated gene as a diagnostic tool for the detection of Trypanosoma brucei rhodesiense. Am J Trop Med Hyg. 2002;67(6):684-690.

15. Berberof M, Pérez-Morga D, Pays E. A receptor-like flagellar pocket glycoprotein specific to Trypanosoma brucei gambiense. Mol Biochem Parasitol. 2001;113(1):127-138.

16. Koffi M, De Meeûs T, Bucheton B, et al. Population genetics of Trypanosoma brucei gambiense, the agent of sleeping sickness in Western Africa. Proc Natl Acad Sci U S A. 2009;106(1):209-214.

17. Vickerman K. Developmental cycles and biology of pathogenic trypanosomes. Br Med Bull. 1985;41(2):105-114.

18. Vickerman K, Tetley L, Hendry KA, Turner CM. Biology of African trypanosomes in the tsetse fly. Biol Cell. 1988;64(2):109-119.

19. Sharma R, Gluenz E, Peacock L, Gibson W, Gull K, Carrington M. The heart of darkness: growth and form of Trypanosoma brucei in the tsetse fly. Trends Parasitol. 2009;25(11):517-524.

20. MacGregor P, Matthews KR. New discoveries in the transmission biology of sleeping sickness parasites: applying the basics. J Mol Med (Berl). 2010;88(9):865-871.

21. Oberle M, Balmer O, Brun R, Roditi I. Bottlenecks and the Maintenance of Minor Genotypes during the Life Cycle of Trypanosoma brucei. PLoS Pathog. 2010;6(7):e1001023.

22. Rotureau B, Van Den Abbeele J. Through the dark continent: African trypanosome development in the tsetse fly. Front Cell Infect Microbiol. 2013;3:53.1-7.

23. Dyer NA, Rose C, Ejeh NO, Acosta-Serrano A. Flying tryps: survival and maturation of trypanosomes in tsetse flies. Trends Parasitol. 2013;29(4):188-196.

24. Roditi I, Lehane MJ. Interactions between trypanosomes and tsetse flies. Curr Opin Microbiol. 2008;11:345-351.

25. Peacock L, Bailey M, Carrington M, Gibson W. Meiosis and Haploid Gametes in the Pathogen Trypanosoma brucei. Curr Biol 2014;24:181-186.

26. Peacock L, Ferris V, Sharma R, et al. Identification of the meiotic life cycle stage of Trypanosoma brucei in the tsetse fly. Proc Natl Acad Sci US A. 2011;108(9):3671-3676.

27. Koffi M, Solano P, Barnabé C, et al. Genetic characterisation of Trypanosoma brucei s.l. using microsatellite typing: new perspectives for the molecular epidemiology of human African trypanosomiasis. Infect Genet Evol. 2007;7(6):675-684.

28. Pépin J, Méda HA. The epidemiology and control of human African trypanosomiasis. Adv Parasitol. 2001;49:71-132.

29. MacGregor P, Szöör B, Savill NJ, Matthews KR. Trypanosomal immune evasion, chronicity and transmission: an elegant balancing act. Nat Rev Microbiol. 2012;10(6):431-438.

30. McCulloch R. Antigenic variation in African trypanosomes: monitoring progress. Trends Parasitol. 2004;20(3):117-121.

31. Pays E. The variant surface glycoprotein as a tool for adaptation in African trypanosomes. Microbes Infect. 2006;8(3):930-937.

32. Pays E, Vanhamme L, Pérez-Morga D. Antigenic variation in Trypanosoma brucei: facts, challenges and mysteries. Curr Opin Microbiol. 2004;7(4):369-374. 
33. Berriman M, Ghedin E, Hertz-Fowler C, et al. The genome of the African trypanosome Trypanosoma brucei. Science. 2005;309(5733): 416-422.

34. Fenn K, Matthews KR. The cell biology of Trypanosoma brucei differentiation. Curr Opin Microbiol. 2007;10(6):539-546.

35. World Health Organization. Control and Surveillance of African Trypanosomiasis. Report of a WHO Expert Committee. WHO Technical Report Series 881. Geneva, Switzerland: World Health Organization; 1998.

36. Robays J, Ebeja Kadima A, Lutumba P, et al. Human African trypanosomiasis amongst urban residents in Kinshasa: a case-control study. Trop Med Int Health. 2004;9(8):869-875.

37. Moloo SK. The distribution of Glossina species in Africa and their natural hosts. Insect Science and its Application. 1993;14:511-527.

38. Elsen P, Amoudi MA, Leclercq M. [The discovery in Saudi Arabia of 2 species of tse-tse flies, vectors of human and animal trypanosomiasis]. Rev Med Liege. 1991;46(4):225-231. French.

39. Molyneux DH. Host-trypanosomes interactions in Glossina. Insect Science and its Application. 1980;1:39-46.

40. Maudlin I, Welburn SC. A single trypanosome is sufficient to infect a tsetse fly. Ann Trop Med Parasitol. 1989;83(4):431-433.

41. Thuita JK, Kagira JM, Mwangangi D, Matovu E, Turner CM, Masiga D. Trypanosoma brucei rhodesiense transmitted by a single tsetse fly bite in vervet monkeys as a model of human African trypanosomiasis. PLoS Negl Trop Dis. 2008;2(5):e238.

42. Aksoy S, Gibson WC, Lehane MJ. Interactions between tsetse and trypanosomes with implications for the control of trypanosomiasis. Adv Parasitol. 2003;53:1-83.

43. Welburn SC, Maudlin I. The nature of the teneral state in Glossina and its role in the acquisition of trypanosome infection in tsetse. Ann Trop Med Parasitol. 1992;86(5):529-536.

44. Torr SJ. The host-oriented behaviour of the tsetse flies (Glossina): the interaction of visual and olfactory stimuli. Physiol Entomol. 1989;14(3):325-340.

45. Tirados I, Esterhuizen J, Rayaisse JB, et al. How do tsetse recognise their hosts? The role of shape in the responses of tsetse (Glossina fuscipes and G. palpalis) to artificial hosts. PLoS Negl Trop Dis. 2011;5(8):e1226.

46. Esterhuizen J, Rayaisse JB, Tirados I, et al. Improving the cost-effectiveness of visual devices for the control of riverine tsetse flies, the major vectors of human African trypanosomiasis. PLoS Negl Trop Dis. 2011;5(8):e1257.

47. Rayaisse JB, Esterhuizen J, Tirados I, et al. Towards an optimal design of target for tsetse control: comparisons of novel targets for the control of Palpalis group tsetse in West Africa. PLoS Negl Trop Dis. 2011;5(9):e1332.

48. Saini RK, Hassanali A. A 4-alkyl-substituted analogue of guaiacol shows greater repellency to savannah tsetse (Glossina spp.). J Chem Ecol. 2007;33(5):985-995.

49. Hargrove JW. The effect of human presence on the behaviour of tsetse (Glossina spp.) (Diptera, Glossinidae) near a stationary ox. Bull Entomol Res. 1976;66(1):173-178.

50. Torr SJ, Chamisa A, Mangwiro TN, Vale GA. Where, when and why do tsetse contact humans? Answers from studies in a national park of Zimbabwe. PLoS Negl Trop Dis. 2012;6(8):e1791.

51. Rayaisse JB, Tirados I, Kaba D, et al. Prospects for the development of odour baits to control the tsetse flies Glossina tachinoides and G. palpalis s.1. PLoS Negl Trop Dis. 2010;4(3):e632.

52. Sané B, Laveissière C, Méda AH. [Diversity of feeding behavior of Glossina palpalis palpalis in the forest belt of the Ivory Coast: relation to the prevalence of human African trypanosomiasis]. Trop Med Int Health. 2000;5(1):73-78. French.

53. Torr SJ, Maudlin I, Vale GA. Less is more: restricted application of insecticide to cattle to improve the cost and efficacy of tsetse control. Med Vet Entomol. 2007;21(1):53-64.

54. Bouyer J, Stachurski F, Kaboré I, Bauer B, Lancelot R. Tsetse control in cattle from pyrethroid footbaths. Prev Vet Med. 2007;78(3-4):223-238.
55. Challier A. The ecology of tsetse (Glossina spp.) (Diptera, Glossinidae): a review (1970-1981). Insect Science and its Application. 1982;3(2-3):97-143.

56. Baker RD. Modelling the probability of a single trypanosome infecting a tsetse fly. Ann Trop Med Parasitol. 1991;85(4):413-415.

57. Cordon-Obras C, García-Estébanez C, Ndong-Mabale N, et al. Screening of Trypanosoma brucei gambiense in domestic livestock and tsetse flies from an insular endemic focus (Luba, Equatorial Guinea). PLoS Negl Trop Dis. 2010;4(6):e704.

58. Funk S, Nishiura H, Heesterbeek H, Edmunds WJ, Checchi F. Identifying transmission cycles at the human-animal interface: the role of animal reservoirs in maintaining gambiense human african trypanosomiasis. PLoS Comput Biol. 2013;9(1):e1002855.

59. Woodruff AW, Evans DA, Owino NO. A healthy carrier of African trypanosomiasis. J Infect. 1982;5:89-92.

60. Jamonneau V, Bucheton B, Kaboré J, et al. Revisiting the immune trypanolysis test to optimise epidemiological surveillance and control of sleeping sickness in West Africa. PLoS Negl Trop Dis. 2010;4(12):e917.

61. Checchi F, Filipe JA, Barrett MP, Chandramohan D. The natural progression of Gambiense sleeping sickness: what is the evidence? PLoS Negl Trop Dis. 2008;2(12):e303.

62. Murray M, Morrison WI, Whitelaw DD, Host susceptibility to African trypanosomiasis: trypanotolerance. Adv Parasitol. 1982;21: $1-68$.

63. Naessens J. Bovine trypanotolerance: A natural ability to prevent severe anaemia and haemophagocytic syndrome? Int J Parasitol. 2006;36:521-528.

64. Duke HL. Trypanosoma gambiense in monkeys and ruminants; prolonged infection, immunity and superinfection. Parasitology. 1931;23(3):325-345.

65. Van Hoof LM. Observations on trypanosomiasis in the Belgian Congo. Trans R Soc Trop Med Hyg. 1947;40(6):728-761.

66. Molyneux DH. Animal reservoirs and Gambian trypanosomiasis. Ann Soc Belg Med Trop. 1973;53(6):605-618.

67. Mehlitz D, Zillmann U, Scott CM, Godfrey DG. Epidemiological studies on the animal reservoir of Gambiense sleeping sickness. Part III. Characterization of trypanozoon stocks by isoenzymes and sensitivity to human serum. Tropenmed Parasitol. 1982;33(2): 113-118.

68. Kageruka P. [Animal reservoir of Trypanosoma (Trypanozoon) brucei gambiense in Central Africa]. Ann Soc Belg Med Trop. 1989;69 Suppl 1: 155-163; discussion 212-214. French.

69. Makumyaviri A, Mehlitz D, Kageruka P, Kazyumba GL, Molisho D. [Animal reservoir hosts of Trypanosoma brucei gambiense in Zaire: trypanosome infections in two foci in Bas-Zaire]. Trop Med Parasitol. 1989;40(3):258-262. French.

70. Jamonneau V, Ravel S, Koffi M, et al. Mixed infections of trypanosomes in tsetse and pigs and their epidemiological significance in a sleeping sickness focus of Côte d'Ivoire. Parasitology. 2004; 129(Pt 6):693-702.

71. Penchenier L, Alhadji D, Bahébéqué S, Simo G, Laveissière C, Cuny G. Spontaneous cure of domestic pigs experimentally infected by Trypanosoma brucei gambiense. Implications for the control of sleeping sickness. Vet Parasitol. 2005;133(1):7-11.

72. Njiokou F, Laveissière $\mathrm{C}$, Simo $\mathrm{G}$, et al. Wild fauna as a probable animal reservoir for Trypanosoma brucei gambiense in Cameroon. Infect Genet Evol. 2006;6(2):147-153.

73. Cordon-Obras C, Berzosa P, Ndong-Mabale N, et al. Trypanosoma brucei gambiense in domestic livestock of Kogo and Mbini foci (Equatorial Guinea). Trop Med Int Health. 2009;14(5):535-541.

74. Njiokou F, Nimpaye H, Simo G, et al. Domestic animals as potential reservoir hosts of Trypanosoma brucei gambiense in sleeping sickness foci in Cameroon. Parasite. 2010;17(1):61-66.

75. Balyeidhusa AS, Kironde FA, Enyaru JC. Apparent lack of a domestic animal reservoir in Gambiense sleeping sickness in northwest Uganda. Vet Parasitol. 2012;187(1-2):157-167. 
76. Schütt ID, Mehlitz D. On the persistence of human serum resistance and isoenzyme patterns of Trypanozoon in experimentally infected pigs. Acta Trop. 1981;38(4):367-373.

77. Paquet C, Castilla J, Mbulamberi D, Beaulieu MF, Gastellu Etchegorry MG, Moren A. [Trypanosomiasis from Trypanosoma brucei gambiense in the center of north-west Uganda. Evaluation of 5 years of control (1987-1991)]. Bull Soc Pathol Exot. 1995;88(1): 38-41. French.

78. Ruiz-Postigo JA, Franco JR, Lado M, Simarro PP. Human African trypanosomiasis in South Sudan: how can we prevent a new epidemic? PLoS Negl Trop Dis. 2012;6(5):e1541.

79. Robays J, Bilengue MM, Van der Stuyft P, Boelaert M. The effectiveness of active population screening and treatment for sleeping sickness control in the Democratic Republic of Congo. Trop Med Int Health. 2004;9(5):542-550.

80. Simarro PP, Franco JR, Ndongo P, Nguema E, Louis FJ, Jannin J. The elimination of Trypanosoma brucei gambiense sleeping sickness in the focus of Luba, Bioko Island, Equatorial Guinea. Trop Med Int Health. 2006;11(5):636-646.

81. Dje NN, Miezan TW, N'guessan P, Brika P, Doua F, Boa F. [Geographic distribution of trypanosomiasis treated in Ivory Coast from 1993 to 2000]. Bull Soc Pathol Exot. 2002;95(5):359-361. French.

82. Asonganyi T, Hengy C, Louis JP, Ghogomu NA. Reactivation of an old sleeping sickness focus in Mamfe (Cameroon): epidemiological, immunological and parasitological findings. Rev Epidemiol Sante Publique. 1991;39(1):55-62.

83. Checchi F, Cox AP, Chappuis F, Priotto G, Chandramohan D, Haydon DT. Prevalence and under-detection of gambiense human African trypanosomiasis during mass screening sessions in Uganda and Sudan. Parasit Vectors. 2012;5:157.

84. Welburn SC, Maudlin I, Simarro PP. Controlling sleeping sickness a review. Parasitology. 2009;136(14):1943-1949.

85. Hide G, Tait A, Maudlin I, Welburn SC. The origins, dynamics and generation of Trypanosoma brucei rhodesiense epidemics in East Africa. Parasitol Today. 1996;12(2):50-55.

86. Waiswa C, Olaho-Mukani W, Katunguka-Rwakishaya E. Domestic animals as reservoirs for sleeping sickness in three endemic foci in south-eastern Uganda. Ann Trop Med Parasitol. 2003;97(2): 149-155.

87. von Wissmann B, Machila N, Picozzi K, et al. Factors associated with acquisition of human infective and animal infective trypanosome infections in domestic livestock in Western Kenya. PLoS Negl Trop Dis. 2011;5(1):e941.

88. Njagu Z, Mihok S, Kokwaro E, Verloo D. Isolation of Trypanosoma brucei from the monitor lizard (Varanus niloticus) in an endemic focus of Rhodesian sleeping sickness in Kenya. Acta Trop. 1999;72(2):137-148.

89. Migchelsen SJ, Büscher P, Hoepelman AI, Schallig HD, Adams ER. Human African trypanosomiasis: a review of non-endemic cases in the past 20 years. Int J Infect Dis. 2011;15(8):e517-e524.

90. Welburn SC, Picozzi K, Fèvre EM, et al. Identification of humaninfective trypanosomes in animal reservoir of sleeping sickness in Uganda by means of serum-resistance-associated (SRA) gene. Lancet. 2001;358(9298):2017-2019.

91. Roberts LW, Wellde BT, Reardon MJ, Onyango FK. Mechanical transmission of Trypanosoma brucei rhodesiense by Glossina morsitans morsitans (Diptera:Glossinidae). Ann Trop Med Parasitol. 1989; 83 Suppl 1:127-131.

92. Sina G, Testa G, Triolo N, Trova P, Cramet B. [Some new cases of congenital human African trypanosomiasis (T. gambiense)]. Med Trop (Mars). 1979;39(1):57-63. French.

93. Kazyumba L, Wery M, Ruppol JF. Congenital transmission of Trypanosoma gambiense. Ann Soc Belg Med Trop. 1978;58(1): 65-66.

94. Lindner AK, Priotto G. The unknown risk of vertical transmission in sleeping sickness - a literature review. PLoS Negl Trop Dis. 2010;4(12):e783.
95. Herwaldt BL. Laboratory-acquired parasitic infections from accidental exposures. Clin Microbiol Rev. 2001;14(4):659-688.

96. Hira PR, Husein SF. Some transfusion-induced parasitic infections in Zambia. J Hyg Epidemiol Microbiol Immunol. 1979;23(4):436-444.

97. Martín-Dávila P, Fortún J, López-Vélez R, et al. Transmission of tropical and geographically restricted infections during solid-organ transplantation. Clin Microbiol Rev. 2008;21(1):60-96.

98. Rocha G, Martins A, Gama G, Brandão F, Atouguia J. Possible cases of sexual and congenital transmission of sleeping sickness. Lancet. 2004;363(9404):247.

99. Grebaut P, Bodo JM, Assona A, et al. [Risk factors for human African trypanosomiasis in the Bipindi region of Cameroon]. Med Trop (Mars). 2001;61(4-5):377-383. French.

100. Kohagne TL, M'eyi MP, Kamkuimo RG, Kaba D, Louis JF, Mimpfoundi R. Transmission of human African trypanosomiasis in the Komo-Mondah focus, Gabon. Pan Afr Med J. 2011;8:36.

101. Moore A, Richer M, Enrile M, Losio E, Roberts J, Levy D. Resurgence of sleeping sickness in Tambura County, Sudan. Am J Trop Med Hyg. 1999;61(2):315-318.

102. Henry MC, Ruppol JF, Bruneel H. [Distribution of infection by T. brucei gambiense in a population of Bandundu in the Republic of Zaire]. Ann Soc Belg Med Trop. 1982;62(4):301-313. French.

103. Courtin F, Jamonneau V, Camara M, et al. A geographical approach to identify sleeping sickness risk factors in a mangrove ecosystem. Trop Med Int Health. 2010;15(8):881-889.

104. Meda AH, Laveissiere C, De Muynck A, Doua F, Diallo PB. [Risk factors for human African trypanosomiasis in the endemic foci of Ivory Coast]. Med Trop (Mars). 1993;53(1):83-92. French.

105. Fournet F, Traoré S, Hervouët JP. Effects of urbanization on transmission of human African trypanosomiasis in a suburban relict forest area of Daloa, Côte d'Ivoire. Trans R Soc Trop Med Hyg. 1999;93(2): 130-132.

106. Grébaut P, Bena JM, Manzambi EZ, et al. Characterization of sleeping sickness transmission sites in rural and periurban areas of Kinshasa (République Démocratique du Congo). Vector Borne Zoonotic Dis. 2009;9(6):631-636.

107. Khonde N, Pépin J, Niyonsenga T, Milord F, De Wals P. Epidemiological evidence for immunity following Trypanosoma brucei gambiense sleeping sickness. Trans R Soc Trop Med Hyg. 1995;89(6): 607-611.

108. Fischer A, Simarro PP, Franco JR, Becher H, Steverding D. Increased trypanolytic activity in sera of sleeping sickness patients after chemotherapy. Trop Med Int Health. 2001;6(12):1070-1074.

109. Vanhecke C, Guevart E, Ezzedine K, et al. D. [Human African trypanosomiasis in mangrove epidemiologic area. Presentation, diagnosis and treatment in Guinea, 2005-2007]. Pathol Biol (Paris). 2010;58(1):110-116. French.

110. Abel PM, Kiala G, Lôa V, et al. Retaking sleeping sickness control in Angola. Trop Med Int Health. 2004;9(1):141-148.

111. Khonde N, Pépin J, Niyonsenga T, De Wals P. Familial aggregation of Trypanosoma brucei gambiense trypanosomiasis in a very high incidence community in Zaire. Trans R Soc Trop Med Hyg. 1997;91(5): 521-524.

112. Henry MC. [Importance of familial contamination in Trypanosoma brucei gambiense trypanosomiasis]. Bull Soc Pathol Exot Filiales. 1981;74(1):65-71. French.

113. Kinung'hi SM, Malele II, Kibona SN, et al. Knowledge, attitudes and practices on tsetse and sleeping sickness among communities living in and around Serengeti National Park, Tanzania. Tanzan Health Res Bull. 2006;8(3):168-172. http://www.who.int/neglected.diseases/ NTD_Roadmap_2012_Fullversion.pdf

114. Zoller T, Fèvre EM, Welburn SC, Odiit M, Coleman PG. Analysis of risk factors for $\mathrm{T}$. brucei rhodesiense sleeping sickness within villages in south-east Uganda. BMC Infect Dis. 2008;8:88.

115. Allsopp R. The role of game animals in the maintenance of endemic and enzootic trypanosomiases in the Lambwe Valley, South Nyanza District, Kenya. Bull World Health Organ. 1972;47(6):735-746.

116. Vale GA, Chamisa A, Mangwiro C, Torr SJ. A neglected aspect of the epidemiology of sleeping sickness: the propensity of the tsetse fly vector to enter houses. PLoS Negl Trop Dis. 2013;7(2):e2086. 
117. Okia M, Mbulamberi DB, De Muynck A. Risk factors assessment for T. b. rhodesiense sleeping sickness acquisition in S.E. Uganda. A case-control study. Ann Soc Belg Med Trop. 1994;74(2):105-112.

118. Wyatt GB, Boatin BA, Wurapa FK. Risk factors associated with the acquisition of sleeping sickness in north-east Zambia; a case-control study. Ann Trop Med Parasitol. 1985;79(4):385-392.

119. Smith DH, Pepin J, Stich AH. Human African trypanosomiasis: an emerging public health crisis. Br Med Bull. 1998;54(2):341-355.

120. Jelinek T, Bisoffi Z, Bonazzi L, et al; European Network on Imported Infectious Disease Surveillance. Cluster of African trypanosomiasis in travelers to Tanzanian national parks. Emerg Infect Dis. 2002;8(6): 634-635.

121. World Health Organization. Working to Overcome the Global Impact of Neglected Tropical Diseases. First WHO Report on Neglected Tropical diseases. WHO/HTM/NTD 2010/1. Geneva, Switzerland: World Health Organization; 2010. Available from: http://whqlibdoc. who.int/publications/2010/9789241564090_eng.pdf. Accessed January 20, 2014.

122. Lutumba P, Makieya E, Shaw A, Meheus F, Boelaert M. Human African trypanosomiasis in a rural community, Democratic Republic of Congo. Emerg Infect Dis. 2007;13(2):248-254.

123. Mpanya A, Hendrickx D, Vuna M, et al. Should I get screened for sleeping sickness? A qualitative study in Kasai province, Democratic Republic of Congo. PLoS Negl Trop Dis. 2012;6(1):e1467.

124. De Raadt P. African sleeping sickness today. Trans $R$ Soc Trop Med Hyg. 1976;70(2):114-116.

125. Louis FJ, Simarro PP. [Rough start for the fight against sleeping sickness in French equatorial Africa]. Med Trop (Mars). 2005;65(3): 251-257. French.

126. Steverding D. The history of African trypanosomiasis. Parasit Vectors. 2008;1(1):3.

127. World Health Organization. WHO Report on Global Surveillance of Epidemic-Prone Infectious Diseases. Geneva, Switzerland: World Health Organization; 2000. Available from: http://whqlibdoc. who.int/hq/2000/WHO_CDS_CSR_ISR_2000.1.pdf. Accessed December 21, 2013.

128. Franco JR, Simarro PP, Diarra A, Ruiz-Postigo JA, Jannin JG. The journey towards elimination of gambiense human African trypanosomiasis: Not far, nor easy. Parasitology. 2014;141(6):748-760.

129. Ekwanzala M, Pépin J, Khonde N, Molisho S, Bruneel H, De Wals P. In the heart of darkness: sleeping sickness in Zaire. Lancet. 1996;348(9039):1427-1430.

130. Stanghellini A, Josenando T. The situation of sleeping sickness in Angola: a calamity. Trop Med Int Health. 2001;6(5):330-334.

131. Moore A, Richer M. Re-emergence of epidemic sleeping sickness in southern Sudan. Trop Med Int Health. 2001;6(5):342-347.

132. Louis FJ, Simarro PP, Lucas P. [Sleeping sickness: one hundred years of control strategy evolution]. Bull Soc Pathol Exot. 2002;95(5): 331-336. French.

133. Burke J. [History of the campaign against sleeping sickness in the Congo]. Ann Soc Belges Med Trop Parasitol Mycol. 1971;51: 465-482. French.

134. Simarro PP, Diarra A, Ruiz Postigo JA, Franco JR, Jannin JG. The human African trypanosomiasis control and surveillance programme of the World Health Organization 2000-2009: the way forward. PLoS Negl Trop Dis. 2011;5(2):e1007.

135. Simarro PP, Franco JR, Diarra A, Ruiz Postigo JA, Jannin J. Diversity of human African trypanosomiasis epidemiological settings requires fine-tuning control strategies to facilitate disease elimination. Res Rep Trop Med. 2013;2013(4):1-6.

136. Mumba D, Bohorquez E, Messina J, et al. Prevalence of Human African Trypanosomiasis in the Democratic Republic of the Congo. PLoS Negl Trop Dis. 2011;5(8):e1246.

137. Kaare MT, Picozzi K, Mlengeya T, et al. Sleeping sickness a re-emerging disease in the Serengeti? Travel Med Infect Dis. 2007;5(2):117-124.
138. Odiit M, Bessell PR, Fèvre EM, et al. Using remote sensing and geographic information systems to identify villages at high risk for rhodesiense sleeping sickness in Uganda. Trans $R$ Soc Trop Med Hyg. 2006;100(4):354-362

139. Abaru DE. Sleeping sickness in Busoga, Uganda, 1976-1983. Trop Med Parasitol. 1985;36(2):72-76.

140. Morris KR. The epidemiology of sleeping sickness in East Africa. I. A sleeping sickness outbreak in Uganda in 1957. Trans $R$ Soc Trop Med Hyg. 1959;53:384-393.

141. Berrang Ford L. Civil conflict and sleeping sickness in Africa in general and Uganda in particular. Confl Health. 2007;1:6.

142. Selby R, Bardosh K, Picozzi K, Waiswa C, Welburn SC. Cattle movements and trypanosomes: restocking efforts and the spread of Trypanosoma brucei rhodesiense sleeping sickness in post-conflict Uganda. Parasit Vectors. 2013;6(1):281.

143. Welburn SC, Fèvre EM, Coleman PG, Odiit M, Maudlin I. Sleeping sickness: a tale of two diseases. Trends Parasitol. 2001;17(1): 19-24.

144. Simarro PP, Cecchi G, Paone M, et al. The Atlas of human African trypanosomiasis: a contribution to global mapping of neglected tropical diseases. Int J Health Geogr. 2010;9:57.

145. Welburn SC, Maudlin I. Priorities for the elimination of sleeping sickness. Adv Parasitol. 2012;79:299-337.

146. World Health Organization. Report of a WHO Meeting on Elimination of African Trypanosomiasis (Trypanosoma brucei gambiense). Geneva, 3-5 December 2012. Geneva, Switzerland: World Health Organization; 2012. Available from: http://apps.who.int/ iris/bitstream/10665/79689/1/WHO_HTM_NTD_IDM_2013.4_eng. pdf. Accessed December 21, 2013.

147. Cecchi G, Paone M, Franco JR, et al. Towards the Atlas of human African trypanosomiasis. Int J Health Geogr. 2009;8:15.

148. World Health Organization. Mapping the foci of human African trypanosomiasis. Available from: http://www.who.int/ trypanosomiasis_african/country/foci_AFRO/en/index.html. Accessed January 20, 2014.

149. Simarro PP, Cecchi G, Franco JR, et al. Estimating and mapping the population at risk of sleeping sickness. PLoS Negl Trop Dis. 2012;6(10):e1859.

150. World Health Organization. Accelerating Work to Overcome the Global Impact of Neglected Tropical Diseases: A Roadmap for Implementation. Geneva, Switzerland: World Health Organization; 2012. Available at http://www.who.int/neglected_diseases/NTD_RoadMap_2012_Fullversion.pdf. Accessed January 20, 2014

151. Simarro PP, Cecchi G, Franco JR, et al. Mapping the capacities of fixed health facilities to cover people at risk of gambiense human African trypanosomiasis. Int J Health Geogr. 2014:13:4.

152. Intergovernmental Panel on Climate Change. The Regional Impacts of Climate Change: An Assessment of Vulnerability. IPCC, 1997-Watson RT, Zinyowera MC, Moss RH, editors. Cambridge University Press, UK.

153. Hulme M, Doherty R, Ngara T, New M, Lister D. African climate change: 1900-2100. Clim Res. 2001;17:145-168.

154. Cecchi G, Mattioli RC, Slingenbergh J, De La Rocque S. Land cover and tsetse fly distributions in sub-Saharan Africa. Med Vet Entomol. 2008;22(4):364-373.

155. Courtin F, Jamonneau V, Duvallet G, et al. Sleeping sickness in West Africa (1906-2006): changes in spatial repartition and lessons from the past. Trop Med Int Health. 2008;13(3):334-344.

156. Courtin F, Rayaissé JB, Tamboura I, et al. Updating the northern tsetse limit in Burkina Faso (1949-2009): impact of global change. Int J Environ Res Public Health. 2010;7(4):1708-1719.

157. Tongue LK, Mavoungou JF, Kamkumo RG, et al. Human African trypanosomiasis in suburban and urban areas: a potential challenge in the fight against the disease. J Clin Exp Pathol. 2012; (Suppl 3):002. 
158. Fèvre EM, Coleman PG, Odiit M, Magona JW, Welburn SC, Woolhouse ME. The origins of a new Trypanosoma brucei rhodesiense sleeping sickness outbreak in eastern Uganda. Lancet. 2001;358(9282): 625-628.

159. Fèvre EM, Picozzi K, Fyfe J, et al. A burgeoning epidemic of sleeping sickness in Uganda. Lancet. 2005;366(9487):745-747.
160. Moore S, Shrestha S, Tomlinson KW, Vuong H. Predicting the effect of climate change on African trypanosomiasis: integrating epidemiology with parasite and vector biology. $J R$ Soc Interface. 2012;9(70):817-830.

\section{Publish your work in this journal}

Clinical Epidemiology is an international, peer-reviewed, open access journal focusing on disease and drug epidemiology, identification of risk factors and screening procedures to develop optimal preventative initiatives and programs. Specific topics include: diagnosis, prognosis, treatment, screening, prevention, risk factor modification, systematic

Submit your manuscript here: http://www.dovepress.com/clinical-epidemiology-journal

\section{Dovepress}

reviews, risk \& safety of medical interventions, epidemiology \& biostatical methods, evaluation of guidelines, translational medicine, health policies \& economic evaluations. The manuscript management system is completely online and includes a very quick and fair peer-review system, which is all easy to use. 